\title{
New genus of primitive wombat (Vombatidae, Marsupialia) from Miocene deposits in the Riversleigh World Heritage Area (Queensland, Australia)
}

\author{
Philippa Brewer, Michael Archer, Suzanne J. Hand, and Richard Abel
}

\begin{abstract}
A new genus of primitive wombat, described here, is the most complete early wombat found. Two partial maxillae, as well as isolated teeth, were found within the Riversleigh World Heritage Area in northwestern Queensland, Australia. Previous to this, only a single species of wombat (Rhizophascolonus crowcrofti) was known from deposits older than $10 \mathrm{Ma}$, despite an estimated divergence date of $40 \mathrm{Ma}$ between wombats and their closest living relative, the koala. We performed a phylogenetic analysis incorporating the new taxon and using dental, cranial and postcranial characters as well as multiple outgroups in order to control for the diverse specialisations of closely related families and the continuing problem of recognising homologies within these groups. The results indicate a sister relationship between the new taxon and $R$. crowcrofti relative to all other wombats. Based on detailed comparisons between the cheek teeth of wombats, we propose a model which explains the observed differences in cheek tooth form and function in this group. If this model is correct, it could be used to map morphology against diet, and potentially climate.
\end{abstract}

Brewer, Philippa. Department of Earth Sciences, Natural History Museum, London SW7 5BD.

p.brewer@nhm.ac.uk

Archer, Michael. School of Biological, Earth \& Environmental Sciences, University of New South Wales, Sydney, 2052, New South Wales, Australia. m.archer@unsw.edu.au

Hand, Suzanne. School of Biological, Earth \& Environmental Sciences, University of New South Wales, Sydney 2052, New South Wales, Australia. s.hand@unsw.edu.au

Abel, Richard. Faculty of Medicine, Department of Surgery \& Cancer, Imperial College London, London SW7 2AZ, England. richard.abel@imperial.ac.uk

Keywords: new species; new genus; phylogeny; Marsupialia; Vombatidae; Australia

http://zoobank.org/65F19586-5DC7-4DC1-8599-C16743FF024D

PE Article Number: 18.1.9A

Copyright: Palaeontological Association March 2015

Submission: 28 March 2014. Acceptance: 28 January 2015

Brewer, Philippa, Archer, Michael, Hand, Suzanne J., and Abel, Richard. 2015. New genus of primitive wombat (Vombatidae, Marsupialia) from Miocene deposits in the Riversleigh World Heritage Area (Queensland, Australia). Palaeontologia Electronica 18.1.9A: 1-40.

palaeo-electronica.org/content/2015/1060-new-wombat-from-riversleigh 


\section{INTRODUCTION}

Extant wombats are medium- to large-sized (20-200 kg; size categories 2-3 of Andrews et al., 1979, categories D-G of Hernández Fernández et al., 2006) marsupial herbivores endemic to Australia. There are seven recognised genera, of which two are extant; the Common Wombat (Vombatus ursinus) and the Hairy-nosed Wombats (represented by two species, Lasiorhinus latifrons and Lasiorhinus kreftii). All three of the extant species are burrowing grazers. All wombats are classified in the family Vombatidae and together with six extinct families make up the Infraorder Vombatomorphia (Aplin and Archer, 1987). The closest living relative of the wombat is the Koala (represented by a single extant species, Phascolarctos cinereus). Koalas are classified in their own family, Phascolarctidae, and together with the Vombatomorphia comprise the Suborder Vombatiformes (Aplin and Archer, 1987).

Despite an estimated divergence date between the Phascolarctidae and the Vombatidae of $40 \mathrm{Ma}$ (Beck, 2008), only a single monotypic genus of wombat has been described from deposits older than $10 \mathrm{Ma}$. This taxon, Rhizophascolonus crowcrofti, was described on the basis of a single isolated tooth from Lake Ngapakaldi, central Australia (Figure 1; Stirton et al., 1967), although additional specimens have since been described (Brewer et al., 2008).

Wombats are significant in being the only Australian marsupial group to possess hypselodont cheek teeth. Hypselodonty is the condition where the teeth grow continuously throughout life. Hypsodonty (high-crowned molars) and hypselodonty (also known as euhypsodonty; Mones, 1982) are adaptations to high rates of tooth wear and have independently evolved in numerous groups. Examples include the cheek teeth of bovids and lagomorphs, respectively. The evolution of hypselodonty in the Vombatidae is poorly documented owing to the paucity of fossil material. Despite this, the Vombatidae are potentially valuable indicators of changing environmental conditions in Australia during the Neogene (e.g., Myers et al., 2001).

The oldest known hypselodont wombat is Warendja encorensis from the late Miocene of Riversleigh (Figure 1; Brewer et al., 2007). This genus is also found in Pleistocene deposits in South Australia and New South Wales (Flannery and Pledge, 1987; Brewer, 2007), forming a ghost lineage throughout the Pliocene. In addition to Warendja, six additional wombat genera are first found in Plio-

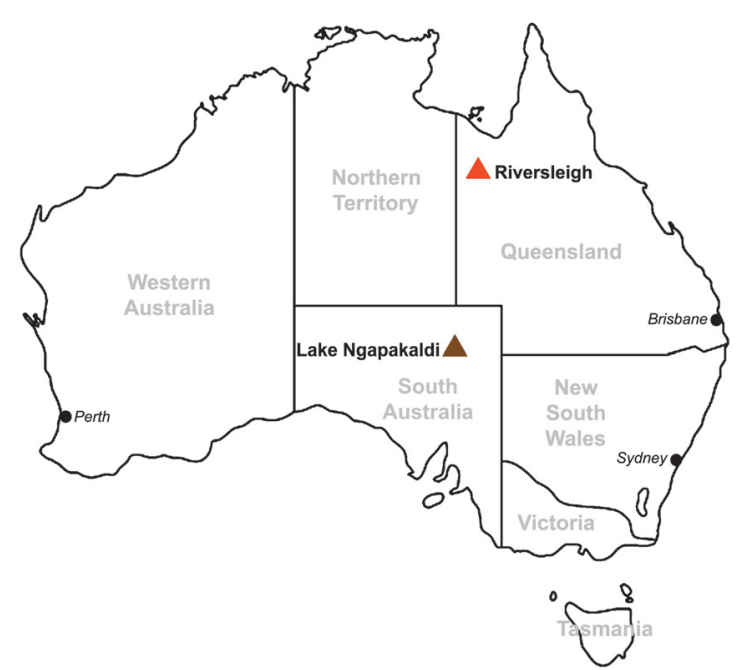

FIGURE 1. Map of Australia showing the location of Miocene wombat fossil sites.

cene deposits, with the greatest diversity of wombats being found in the Pliocene-Pleistocene. Because extant wombats are specialist grazers, it can be hypothesised that their post-Miocene increase in diversity is related to the spread of more open habitats and greater availability of graze. However, each of these taxa almost certainly occupied slightly different niches, and the picture is likely to be more complex.

This paper describes specimens of a new genus and species of primitive wombat from early Miocene deposits within the Riversleigh World Heritage Area in northwest Queensland (Figure 1). The specimens comprise two partial maxillae and isolated teeth, possibly representing as few as two individuals. Despite the small sample size, this new taxon represents the most complete early wombat known.

\section{MATERIALS AND METHODS}

\section{Phylogenetic Analysis}

Of the eight vombatiform families, only vombatids and phascolarctids have extant representatives. Interfamilial relationships within the Vombatiformes are contentious (Archer, 1984; Marshall et al., 1990; Munson, 1992; Murray, 1998; Black et al., 2012). Accordingly, a phylogenetic analysis was performed in which a range of outgroup taxa were selected (Peramelemorphia and Didelphimorphia). The choice of outgroup taxa concurs with the interordinal relationships determined by Beck (2008), constrained in some cases by the availability of postcranial material for some 
taxa. A relatively unspecialised representative of each of the eight vombatiform families was included in the analysis. A total of 16 taxa were coded in the analysis.

The data set consisted of dental, cranial and postcranial characters taken from the literature and personal observations. Where characters were taken from the literature, they were re-scored, where possible, for each of the taxa in the analysis in order to verify the results of others and to ensure consistency. Some characters used by other authors in their phylogenetic analyses were rejected from this analysis because they were found to be highly intraspecifically variable (e.g., presence of frontal-squamosal contact: Springer et al., 1997; Wroe et al., 1998; Horovitz and SánchezVillagra, 2003; Black et al., 2012), or they were not parsimony-informative for any of the taxa examined.

A total of 115 characters were used in the analysis of which 28 are of the type ordered (Wagner) and 87 are of the type unordered. The data matrix was analysed using Paup 4.0b10 (Swofford, 2002) using PaupUp graphical interface (Calendini and Martin, 2005). The branch and bound search option was utilised, using a mixture of ordered and unordered characters (Appendices 1, 2). Multistate characters were treated as polymorphisms. All characters were presumed to have equal weight. Accelerated transformation (ACCTRAN) and delayed transformation (DELTRAN) characterstate optimisation methods were employed. Bootstrap support $(50 \%)$ for clades was determined using 10,000 replicates.

\section{Terminology}

Incisor, premolar and molar homology follows Flower (1867). The position of the molar/premolar boundary follows Luckett (1993). Anatomical nomenclature follows Nomina Anatomica Veterinaria (Frewein et al., 1994) where possible. Exceptions are given in Brewer (2007) and Brewer et al. (2007) or follow terms within the body of the text. Premaxilla is used instead of incisive bone. Jugal is used instead of zygomatic bone. Vombatid systematics follows Dawson (1981, 1983a, 1983b). Higher level systematic nomenclature follows Aplin and Archer (1987). Faunal and chronostratigraphic terminology of the Riversleigh Oligo-Miocene deposits follows Travouillon et al. (2006).

\section{Institutional Abbreviations}

AM F, palaeontology collection at the Australian Museum, Sydney; NMV C, mammalogy collection at the Museum Victoria; NMV P, palaeontology collection at the Museum Victoria, Melbourne; QM F, palaeontology collection at the Queensland Museum, Brisbane; SAM M, zoology collection at the South Australian Museum, Adelaide; SAM P, palaeontology collection at the South Australian Museum, Adelaide; AR, temporary number for palaeontology collection at the University of New South Wales, Sydney; UNSW Z, and UNSW J, zoology collection at the University of New South Wales, Sydney.

\section{SYSTEMATIC PALAEONTOLOGY}

Order DIPROTODONTIA Owen, 1866

Suborder VOMBATIFORMES Woodburne, 1984

Family VOMBATIDAE Burnett, 1830

Genus NIMBAVOMBATUS gen. nov.

zoobank.org/C832B075-FB33-4C41-B5DF-EA48888AA8D3

Etymology. 'Nimba' is the Waanyi (the local Aboriginal language of the Boodjamulla region) word for 'small'. 'Vombatus' means 'wombat-like'.

Diagnosis. As for the species diagnosis until additional species are described.

Nimbavombatus boodjamullensis sp. nov. Figures 2-5

zoobank.org/1D7CD6A8-DB90-4D89-9B2F-7306C2DFDAA5

Etymology of Specific Name. Refers to the Waanyi (the local Aboriginal language of Riversleigh) word for the Riversleigh area (BoodjamuIla).

Holotype. QM F23774 (left maxilla with $\mathrm{C}^{1}, \mathrm{P}^{3}$ and $\mathrm{M}^{1-4}$ )

Paratypes. QM F23725 (left maxilla fragment with $\mathrm{P}^{3}, \mathrm{M}^{1-3}$ and partial alveolus of $\mathrm{M}^{4}$ ); QM F30339 (right $\mathrm{M}^{1}$ ); QM F23773 (left $\mathrm{M}_{\mathrm{x}}$ ); QM F51404 (left $\mathrm{M}_{1}$ ).

Type Locality and Distribution. All of the specimens described here are from the Riversleigh World Heritage Area, northwestern Queensland $\left(19^{\circ} 02^{\prime}, 138^{\circ} 45^{\prime}\right)$. The holotype is from Boid Site East on Godthelp Hill. The paratypes are from Creaser's Ramparts on Hal's Hill. Precise location details for these localities may be obtained on application to the Queensland Museum, Brisbane, Australia.

Geology. Boid Site East and Creaser's Ramparts Site are freshwater limestone deposits which form part of more extensive Oligo-Miocene to Pleistocene limestone deposits within the Riversleigh World Heritage Area (Archer et al., 1989, 1997; Woodhead et al., 2014). Creaser (1997) suggested that Creaser's Ramparts Site formed from a fresh- 


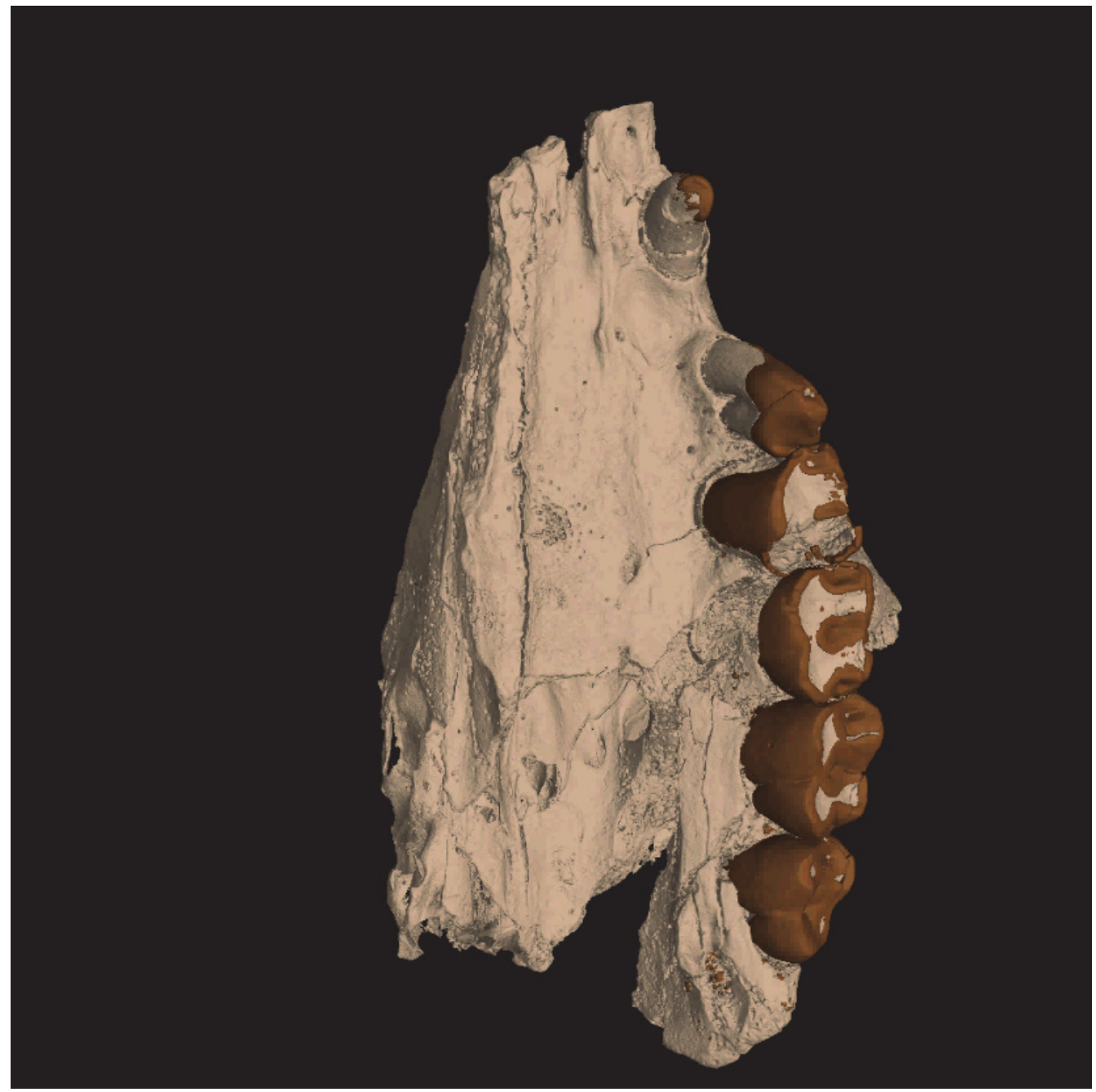

FIGURE 2. An animation of type specimen QM F23774, reduced for web viewing, based on CT data. The specimen was scanned at the Natural History Museum, London using a Metris X-Tek HMX ST 225 system. Volumes were constructed using CT PRO (Metris X-Tek, UK) and visualised using VG Studio Max 2.0 (Volume Graphics, Heidelberg, Germany).

water limestone pool in or at the edge of rainforest and that Boid Site East is a tufa deposit (Creaser, 1997). Arena (2004) classified both sites as vadose cave deposits that were deposited within Depositional Phase 2 (Travouillon et al., 2006).

Age. Boid Site East and Creaser's Ramparts Site group with other sites at Riversleigh in Faunal Zone B (Travouillon et al., 2006; Black et al., 2012, 2013). Faunal Zone B is estimated to be early Miocene in age based on biocorrelation and stage of evolution arguments (Archer et al. 1989, 1997, 1999). Radiometric dating of speleotherms from five Faunal Zone B deposits at Riversleigh produced dates between 16 and $19 \mathrm{Ma}$ (Woodhead et al., 2014).
Specific Diagnosis. Small vombatid with $M^{1}$ length c. $6-7.5 \mathrm{~mm}$, molars are bunodont with stylar cusps reduced to absent, cheek teeth possess roots (three upper molar roots and two lower molar roots), molars have relatively small but broad inflections in enamel height with enamel extending up to $3 \mathrm{~mm}$ below the furcation between the roots on the lingual surface of the upper molars and buccal surface of the lower molars (i.e., the trailing surface), but not extending onto the roots on other surfaces, enamel is up to $0.5 \mathrm{~mm}$ thicker on the trailing surface of the molars relative to the other surfaces, $\mathrm{C}^{1}$ is present as is a posterior incisor $\left(\mathrm{I}^{3}\right.$ and/or $\mathrm{I}^{2}$ ), the ventral root of the zygomatic arch is only $2.5 \mathrm{~mm}$ dorsal to the molar row and there is no infraorbital fossa. 

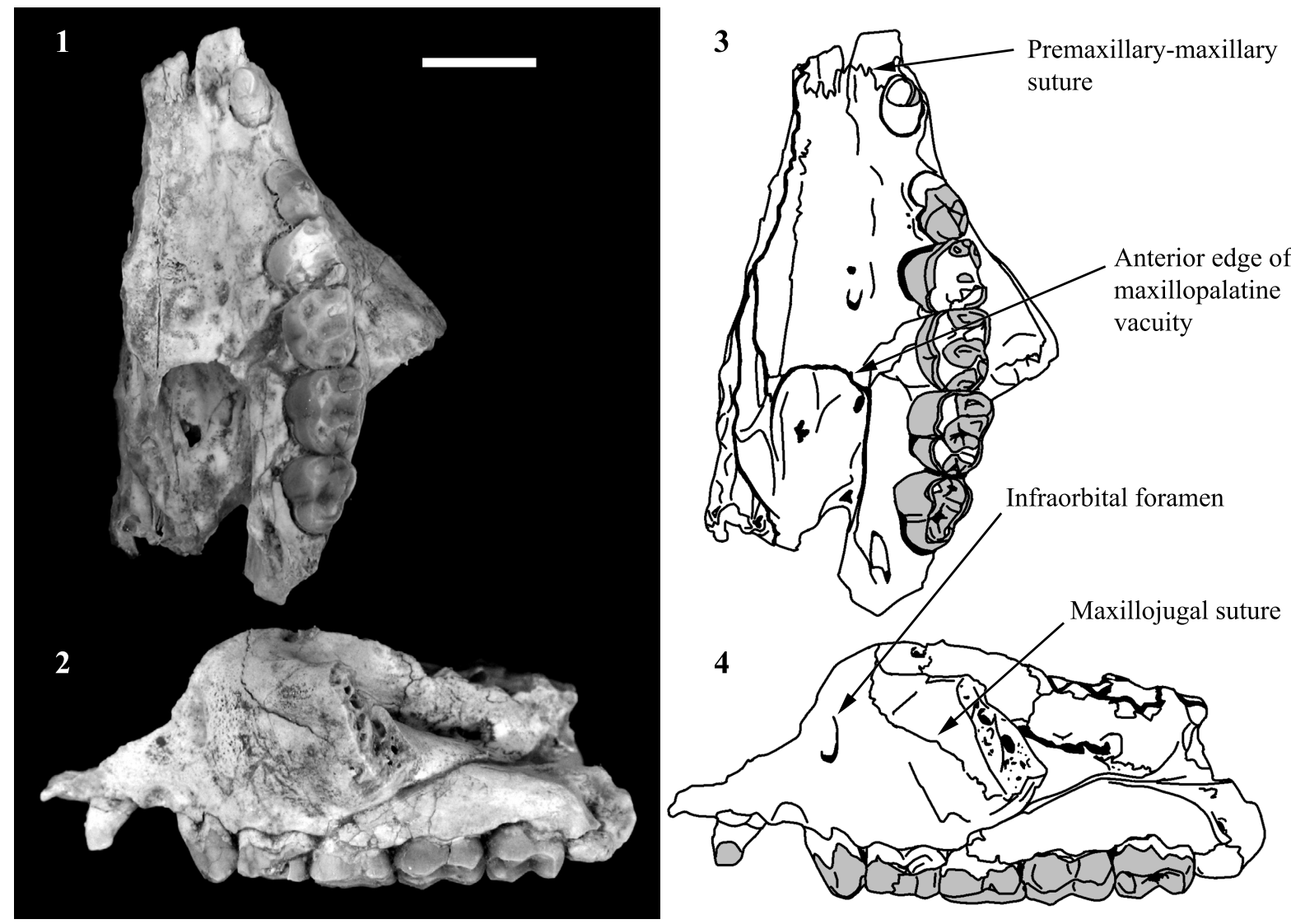

FIGURE 3. Left maxillary fragment of Nimbavombatus boodjamullensis from Boid Site East (QM F23774). Left panel (photographs) of 1, occlusal (ventral) view of tooth row and 2, buccal (lateral) view. Scale bar represents $10 \mathrm{~mm}$. Right panel (line drawings) of 3, occlusal (ventral) view and 4, buccal (lateral) view. Grey shading represents enamel.

\section{Description}

Description of the cranial bones is based on the holotype (QM F23774; Figures 2, 3) unless otherwise specified.

Nasal Cavity. The nasopharyngeal meatus is oval in cross-section and wider (mediolaterally) than tall. The turbinals are preserved dorsal to the posterior moiety of $\mathrm{M}^{1}$ and posteriorly as far as the ventral extent of the cribriform plate (a small portion of which is preserved).

Premaxilla. A $4.0 \mathrm{~mm}$ long sliver of the premaxilla is preserved anterior to the premaxillomaxillary suture on the left palate. The posterior edge of an incisor alveolus forms the anterior tip of this sliver of bone. The premaxillomaxillary suture is approximately level with the anterior edge of $\mathrm{C}^{1}$ between the median palatine suture and the anterolingual tip of $\mathrm{C}^{1}$ on the ventral surface of the palate. The premaxillomaxillary suture intersects the posterior edge of the left incisive foramen midway between the canine and the median palatine suture. The lateral edge of the incisive foramen is emphasised by an anteroposterior ridge that crosses the premaxillomaxillary suture. This ridge is $4.2 \mathrm{~mm}$ medial to the interalveolar margin. On the dorsal surface of the palate (within the nasal cavity) there is a corresponding ridge and sulcus extending posteromedially from the incisive foramen. A minor foramen on the ventral surface of the palate is located close to the interalveolar margin and anterior to $\mathrm{C}^{1}$.

Palatine. The palatine forms part of the lateral wall of the cranium medial to the maxillary sulcus within the orbital region. The dorsoventrally orientated palatolachrymal suture forms the anterior edge of the palatine on this wall. The ventral edge of the palatine is formed by the palatomaxillary suture. The latter is approximately coincident with the maxillary sulcus and intersects the sphenopalatine foramen at the posterolateral edge of the sulcus. Posterior to this the palatomaxillary suture is orientated posterolaterally until it intersects the dorsal posterolateral palatine foramen at the maxillary tuber. The suture curves around the posterior surface of the maxillary tuber and intersects the ventral posterolateral foramen on the posteroventral 


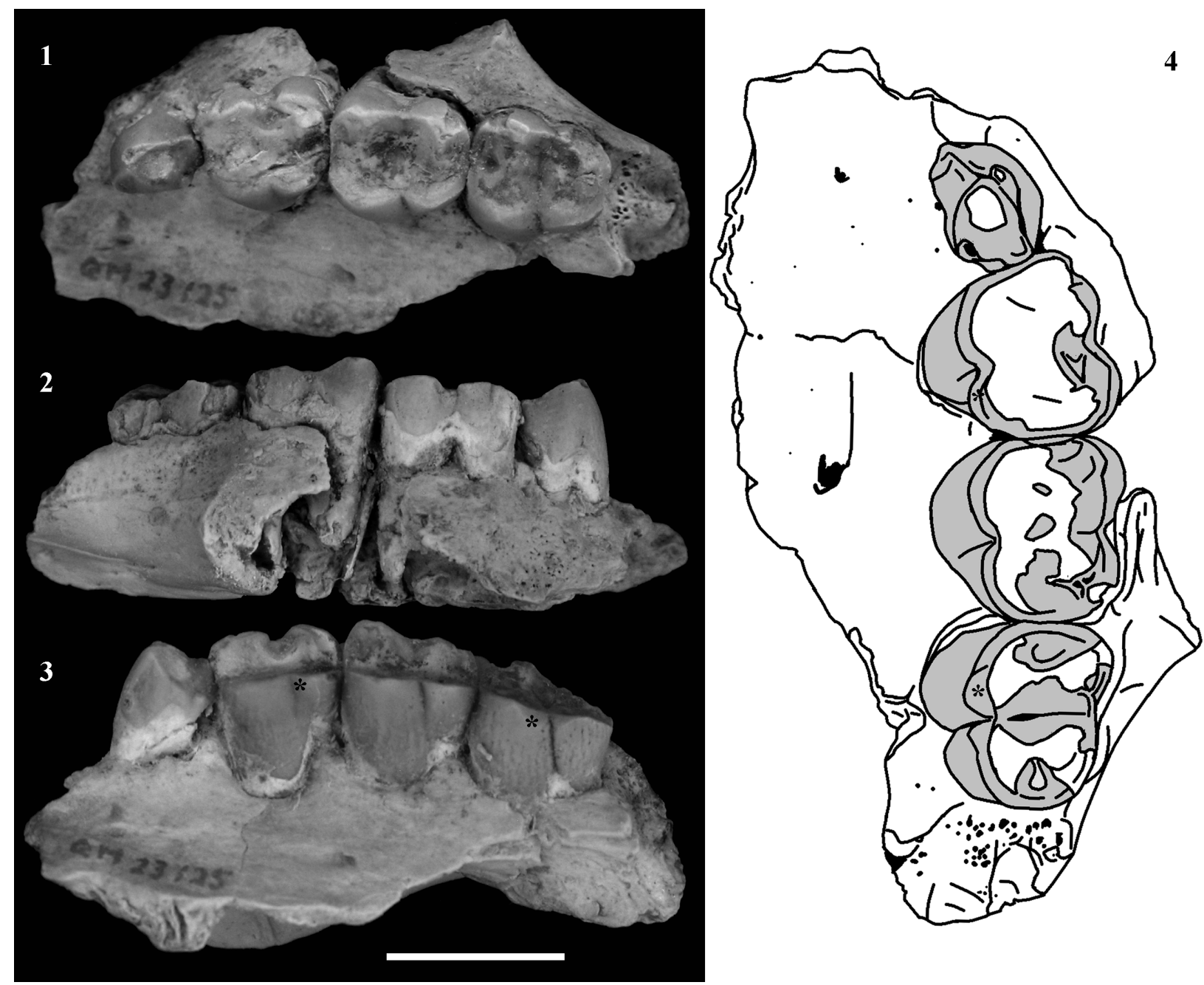

FIGURE 4. Left maxillary fragment of Nimbavombatus boodjamullensis from Creaser's Ramparts Site (QM F23725). Photographs of 1, occlusal (ventral) view, 2, buccal (lateral) view and 3, lingual (medial) view. Scale bar represents 10 $\mathrm{mm} .4$, Line drawing of occlusal (ventral) view. Grey shading represents enamel. Asterisk marks presence of distinctive wear facet on trailing edge enamel (see text for details).

edge of the alveolar process. The suture is indistinct beyond this point. The dorsal and posterior edges of the palatine are not preserved.

Jugal. Only the anteromedial portion of the jugal bone is preserved. The lachrymojugal suture forms the medial edge of the jugal bone. The lateral-most point on the suture is located on the tightly convex dorsal surface of the zygomatic arch. The anterior edge of the jugal is formed by the maxillojugal suture, which curves laterally and posteroventrally down the anterior facial surface as far as the ventral root of the zygomatic arch. This suture cuts dorsomedially across the arch and onto the anterior wall of the orbit where it is mediolaterally orientated almost as far as the lateral wall of the cranium (medial wall of the orbit). The jugal does not contribute to the medial wall of the orbit. The lachrymojugal suture forms the medial edge of the jugal within the orbital region and is dorsoventral in orientation. The jugal between the contact with the maxilla on the anterior wall of the orbit and the dorsal surface of the arch dips steeply posteroventrally.

Lachrymal. The lachrymal is largely intact with only the medial edge missing. The preserved portion is subrectangular in dorsal view. The lachrymal contacts the maxilla at its anterior edge, anteromedial to the zygomatic arch and along its lateral edge within the orbit. The lateral edge of the lachrymal also contacts the jugal on the dorsal surface of the zygomatic arch and on the anterior wall of the orbit. The posterolateral tip of the lachrymal abuts the medial wall of the maxillary sulcus $4 \mathrm{~mm}$ posterior to the maxillary foramen. The posterior 


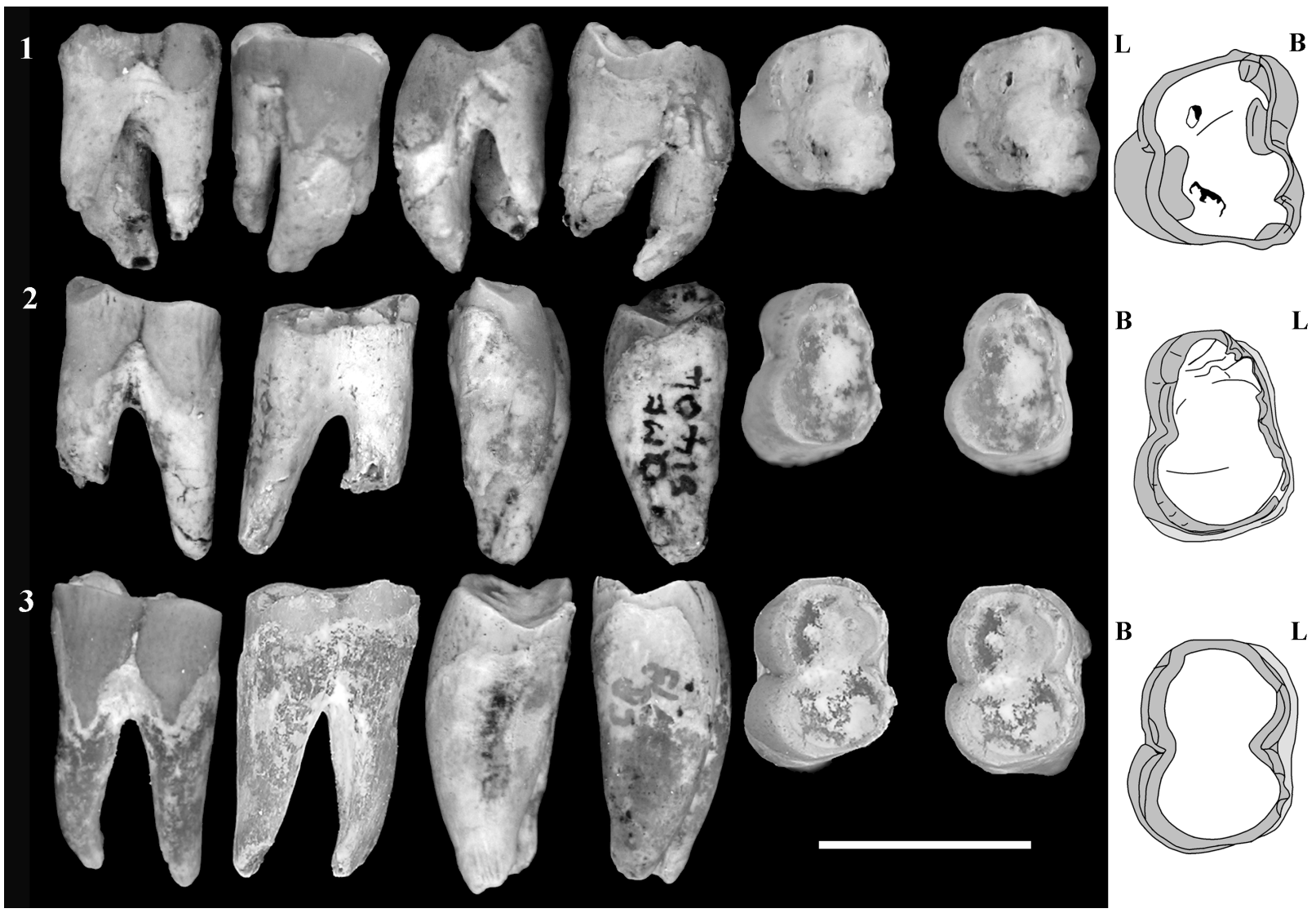

FIGURE 5. Isolated molars of Nimbavombatus boodjamullensis from Creaser's Ramparts. 1, Right $\mathrm{M}^{1}$ (QM F30339). 2, Left $M_{1}$ (QM F51404). 3, Left $M_{x}$ (probably $M_{2}$ or $M_{3}$ ) (QM F23773). From left to right views are: buccal, lingual, anterior, posterior, stereo of occlusal surface and line drawing of occlusal surface. Scale bar for photographs represents $10 \mathrm{~mm}$. Grey shading on line drawings represents enamel. L indicates lingual side, B indicates buccal side.

edge of the lachrymal forms part of the lateral wall of the cranium within the orbit and is bounded posteriorly by the palatine. However, the suture between these bones is not clearly defined.

The lachrymal foramen is anteromedially located on the lachrymal bone in dorsal view. It is medial to the zygomatic arch and on the anteromedial edge of the orbit. The foramen is $1.5 \mathrm{~mm}$ in diameter and approximately circular. Posterior to this, the lachrymal is indented and forms a shallow concavity approximately $4 \mathrm{~mm}$ in diameter on the anteromedial wall of the orbit. The lachrymal canal extends anteromedially from the lachrymal foramen to the nasal cavity. It opens into the latter at a small protuberance and continues as a groove ventral to the opening.

Maxilla. The majority of the left maxilla is preserved, although the anterodorsal portion is missing, including the contact between the maxilla and the premaxilla, nasal and frontal bones.
The maxilla and jugal bones of the infraorbital region form a continuous ventrally and posterolaterally sloping facial surface. There is no infraorbital fossa or facial crest. The ventral surface of the anterior root of the zygomatic arch is mildly convex and forms an almost horizontal shelf in anterior view, 2-2.5 $\mathrm{mm}$ dorsal to the alveolar margin at $\mathrm{M}^{2}$. The lateral surface of the maxilla is almost vertical between $\mathrm{M}^{2}$ and the anterior root of the zygomatic arch.

The maxillojugal suture commences at its anterodorsal contact with the lachrymal and extends laterally and posteroventrally across the facial surface as far as the anteroventral edge of the zygomatic arch. The suture is complex in cross-section with an overall dorsomedial inclination between the anteroventral edge of the arch and the anterior wall of the orbit. The suture is mediolaterally orientated across the anterior wall of the orbit and is $3.3 \mathrm{~mm}$ posteroventral to the dorsal surface of the arch at this point. It meets the lachry- 
mal, anterior to the position of the maxillary foramen. The maxillojugal suture is deeply incised on the anterior surface of the orbit and marks the anterior extent of a shallowly sloping orbital floor. The orbital floor slopes posteroventrally at an angle of approximately $20^{\circ}$ to the alveolar margin, ending at the dorsal posterolateral palatine foramen, just posterior to $\mathrm{M}^{4}$.

Between the alveolar process and the lateral wall of the cranium within the orbit is the maxillary sulcus. The sulcus is deep and well-defined. It is $12 \mathrm{~mm}$ in length and slopes ventrally and posteromedially. It commences at the maxillary foramen and finishes just posterior to the sphenopalatine foramen. The sphenopalatine foramen is ovate and opens directly into the nasal cavity. Anterior and posterior to the sphenopalatine foramen, within the maxillary sulcus, are minor foramina. The maxillary foramen is located $3.2 \mathrm{~mm}$ posterior to the maxillojugal suture. The maxillary foramen and sulcus form a deep incision in the maxilla, resulting in a shelf-like appearance of the anterior part of the floor of the orbit. The anterior orbital floor is laterally continuous with the dorsal surface of the alveolar process.

The anterior part of the maxilla on QM F23774 is broken along a posterodorsally-orientated break that passes anterior to the infraorbital foramen and meets the lachrymal anterior to the lachrymal foramen. The infraorbital foramen is located $6 \mathrm{~mm}$ dorsal to the alveolar margin at $\mathrm{P}^{3}$. It is approximately $7.5 \mathrm{~mm}$ in diameter and generally circular in crosssection. The opening of the foramen faces anteriorly and slightly laterally. $1.5 \mathrm{~mm}$ posterior to the infraorbital foramen, the medial wall of the infraorbital canal is perforated by the opening of the incisivomaxillary canal. Medial to this the numerous septa and vacuities of the alveolar canals are exposed in longitudinal section. The infraorbital canal is $13 \mathrm{~mm}$ in length between the infraorbital foramen and the maxillary foramen.

On the lateral surface of the alveolar process, alveolar jugae increase in prominence anteriorly and are particularly marked either side of the canine. On the ventral surface of the palate on QM F23774 there are a number of minor ridges and sulci located between the incisive foramen and the anterior edge of the maxillary vacuity. Ridges and sulci are not as obvious on the ventral surface of QM F23725. However, two minor palatal foramina, up to $1 \mathrm{~mm}$ in diameter, are present on the palatal surface on the latter specimen. They are located $4.5 \mathrm{~mm}$ medial to the lingual edge of the cheek teeth. The anterior foramen is level with the ante- rior edge of $\mathrm{P}^{3}$, and the posterior foramen is level with the anterior moiety of $\mathrm{M}^{2}$.

There is a large maxillary vacuity that is approximately rectangular in shape, with rounded corners. The anterior edge of the vacuity is level with the posterior edge of $\mathrm{M}^{2}$. The posterior edge of the vacuity is not preserved but appears to extend to at least the anterior moiety of $\mathrm{M}^{4}$. The mediolateral width of the left vacuity is approximately $7.5 \mathrm{~mm}$. The palate is $2.5 \mathrm{~mm}$ in mediolateral width between the vacuity and the lingual edges of the molars. The anterior part of a median process is preserved. It is not clear whether the process partially or wholly divided the maxillary vacuity.

Medial and posterior to $\mathrm{M}^{4}$ on the palatal surface there is an elongated fossa that probably represents the ventral posterolateral palatine foramen. The palatomaxillary suture intersects the dorsal posterolateral palatine foramen on the dorsal surface and curves around onto the ventral surface of the palate, intersecting this probable ventral opening of the posterolateral palatal foramen.

The palate is $16.3 \mathrm{~mm}$ in mediolateral width at $\mathrm{M}^{2}$ and is similarly wide along the length of the cheek tooth row. The palate narrows anterior to $M^{1}$ and is $9.3 \mathrm{~mm}$ in width between the median palatine suture and the interalveolar margin, posterior to the canine. The cheek tooth row is arcuate in ventral view (laterally convex). The buccal contact between $\mathrm{M}^{2}$ and $\mathrm{M}^{3}$ forms the lateral-most point of the arc. The diastema between $\mathrm{P}^{3}$ and $\mathrm{C}^{1}$ is 3.3 $\mathrm{mm}$. The cheek tooth row is $30.7 \mathrm{~mm}$ long. The widest part of the tooth row is represented by the anterior moieties of $\mathrm{M}^{2}$ and $\mathrm{M}^{3}$.

C1. C1 $^{1}$ is preserved only on the left side of $\mathrm{QM}$ F23774 (Figures 2, 3). It is located on the premaxillomaxillary suture, $3.3 \mathrm{~mm}$ anterior to $\mathrm{P}^{3}$ and 4.2 $\mathrm{mm}$ posterior to the anterior edge of the specimen. It is separated from both by a diastema. In occlusal view it is ovate in cross-section. $C^{1}$ is $4.2 \mathrm{~mm}$ in anteroposterior length and $3.5 \mathrm{~mm}$ in buccolingual width measured at the alveolar margin. Length and width constrict towards the crown apex. It is 2.4 $\mathrm{mm}$ in anteroposterior length just below the apex. The posterior surface of the tooth is concave, and the anterior surface is convex in lateral view. The buccal and lingual surfaces are mildly convex. The posterior surface slopes posterobasally at an angle of approximately $65^{\circ}$ to the alveolar margin. The dorsoventral height is $4.7 \mathrm{~mm}$ measured on the buccal side between the alveolar margin and the crown apex. 
Enamel is restricted to the apical half to third of the crown. The enamel is largely restricted to the buccal surface due to a large ovate wear facet on the lingual surface which has penetrated the enamel. The maximum enamel height on the buccal surface is $2 \mathrm{~mm}$. The lingual wear facet is $3 \mathrm{~mm}$ in height and $2.3 \mathrm{~mm}$ in anteroposterior width measured at its widest point, $1.6 \mathrm{~mm}$ from the crown apex. The wear facet is relatively flat and faces slightly posteriorly. Apically, the facet is mildly concave and surrounded entirely by dentine. Basally, the facet is mildly convex and edged by enamel. In buccal view, the apex of the crown slopes posteriorly slightly and is flat to mildly convex. In occlusal view the apical edge is convex buccally.

$\mathrm{P}^{3}$. $\mathrm{P}^{3}$ is preserved on the left side on QM F23774 and QM F23725 (Figures 2-4). In occlusal view the tooth is subovate with the posterior half slightly wider in buccolingual width than the anterior half. $\mathrm{P}^{3}$ leans posteriorly at an angle of $60^{\circ}$ to the alveolar margin on QM F23774. In contrast, on QM F23725 it is more vertically orientated. $\mathrm{P}^{3}$ and $\mathrm{M}^{1}$ contact on the buccal side in occlusal view. In buccal view the occlusal profile is continuous between $\mathrm{P}^{3}$ and $\mathrm{M}^{1}$ on QM F23725, but is stepped on QM $\mathrm{F} 23774$. There is a gap between $\mathrm{P}^{3}$ and $\mathrm{M}^{1}$ just above the alveolar margin.

The occlusal surface is dominated by the paracone, which forms the highest point on this surface. It is located above the posterior half of the anterior root. A crest extends posteriorly, basally and slightly buccally away from the paracone towards a smaller and lower cusp located near the posterior edge of the occlusal surface (the metacone). The crest dips in height midway between these cusps and the occlusal surface either side of this dip is concave. The paraconemetacone crest is located buccal to the midline of the tooth. A crest also extends anterolingually and basally from the paracone. This latter crest terminates in a small cusp on the anterolingual 'corner' of the occlusal surface (the parastyle) on QM F23725. Either side of this steeply inclined crest, the enamel on the anterior and lingual faces of the tooth are slightly troughed.

A slight crest extends posterolingually from the paracone towards a low cusp on the lingual edge of the tooth on QM F23725. This lingual cusp forms the most lingual point on the occlusal surface and is located posterior to the midpoint between anterior and posterior edges of the tooth. A groove separates the lingual cusp from the posterolingual crest of the paracone. Immediately posterior to the lingual cusp is another groove which is a lingual extension of the dip in the crest between the paracone and metacone. Between the paracone, the lingual cusp and the paracone-metacone crest, the occlusal surface is relatively flat and slopes posterolingually towards the posterior basin. Wear of this surface has breached the enamel on QM F23725. A minor crest extends posterolingually from the metacone. On QM F23774, there may be a slight cingulum posterior to this posterolingual crest. The posterolingual crest partially encloses a small posterior basin that is deepest immediately adjacent to the crest.

The long axis of the tooth (the anteroposterior length) is continuous with the arc of the molar row. The outline of the tooth in occlusal view is pinched in (constricted) on the buccal side approximately midway between the anterior and posterior edges of the tooth. The anterior quarter of the buccal surface is relatively flat to concave and faces anterobuccally in occlusal view. The posterior quarter faces posterolingually. The lingual surface is concave in occlusal view between the parastyle and lingual cusp (lingual most point on the tooth). Posterior to this, the lingual surface is also concave and faces posterolingually.

There are two roots; anterior and posterior. The interradicular bifurcation appears to be approximately level with the alveolar margin on both $\mathrm{P}^{3}$ specimens. Both roots are approximately circular in shape (based on QM F23774; the roots on QM F23725 are slightly damaged) and of approximately equal size. The anterior root on QM F23774 is $2.8 \mathrm{~mm}$ in buccolingual width and approximately $2.5 \mathrm{~mm}$ in anteroposterior length. The posterior root QM F23774 is $3.5 \mathrm{~mm}$ in buccolingual width and approximately $2.2 \mathrm{~mm}$ in anteroposterior length.

Enamel height is greater on the buccal side than on the lingual side. A thin tongue of enamel extends as far as the alveolar margin on the anterior half of the buccal surface on QM F23725. A similar tongue of enamel is not present on the posterior half of the tooth and the base of the enamel is $1.5 \mathrm{~mm}$ above the alveolar margin at this latter point. The base of the buccal enamel on QM F23774 is obscured by cementum. On both QM F23725 and QM F23774 buccal enamel height is greatest midway across the roots. On the anterior surface, the base of the enamel slopes basally towards the lingual surface. The posterior surface is obscured by $M^{1}$ but enamel height on this surface appears to be quite small. On the lingual surface, there is a significant decrease in enamel 
height between the anterior edge of the tooth and the posterior third of the tooth.

Upper molars. The upper molars are subrectangular in outline (in occlusal view) and mildly bilobed. The occlusal surface is longer in anteroposterior length than buccolingual width. Crown length decreases slightly below the occlusal surface. Maximum length of the occlusal surface is located just lingual to the buccal margin. Anterior and posterior moieties are wider than long. The anterior moiety is slightly larger than the posterior moiety in anteroposterior length and buccolingual width, particularly towards the posterior of the molar row. The anterior moiety increases in width between the occlusal surface and the alveolar margin due to the sloping lingual surface. In contrast, the posterior moiety generally decreases in width between the occlusal surface and the alveolar margin. These differences in width as a result of distance below the occlusal surface are greatest at the anterior of the molar row.

The widest part of the molar row is across the anterior moiety of $\mathrm{M}^{2}$ or $\mathrm{M}^{3}$. Adjacent molars contact midway between their buccal and lingual margins. Tooth height exposed above the alveoli is greatest on the lingual side relative to the buccal side. Tooth height exposed above the alveoli decreases posteriorly along the molar row.

The constriction between the moieties is more pronounced on the lingual side in occlusal view. In profile it is more pronounced on the buccal side with the lingual constriction wearing to a similar height as that of the anterior and posterior moieties. The constriction is represented on the buccal surface by a vertical groove between the mildly convex moieties. The constriction on the lingual surface slopes posterobasally at an angle of 65 to $85^{\circ}$ to the occlusal surface. This angle generally increases between $\mathrm{M}^{2}$ and $\mathrm{M}^{4}$ (i.e., it approaches vertical on $\mathrm{M}^{4}$ ). The slope of the lingual surface either side of the constriction is shallower immediately anterior to the constriction than posterior to it on $\mathrm{M}^{1-3}$. Away from the occlusal surface, the lingual surface on the posterior moiety slopes slightly buccally.

The occlusal morphology is bunolophodont. There are four main cusps; one in each quadrant (inferred to be the paracone, metacone, protocone and metaconule). All cusps are located at the margin of the tooth crown. A medial crest slopes basally from each cusp and meets the basally sloping medial crest of the opposing cusp. There are thus two weakly developed buccolingual 'lophs': one on the anterior moiety connecting the proto- cone to the paracone and one on the posterior moiety connecting metacone and metaconule.

A transverse (buccolingual) valley connects the buccal and lingual constrictions. The transverse valley is deepest near the midpoint between the buccal and lingual constrictions. This is also the deepest point on the occlusal surface. Between the anterior margin of the tooth and the anterior loph is a basin. This anterior basin is mainly restricted to the buccal half of the occlusal surface. A crest marks the anterior margin of the occlusal surface. A low crest forms the posterobuccal margin of the occlusal surface. The posterior s surface of the posterior loph dips steeply towards this low crest.

Occlusal wear is greatest on $\mathrm{M}^{1}$ and decreases posteriorly along the molar row. As such, the unworn crown morphology presented here is based mostly on $\mathrm{M}^{2-4}$. QM F23774 is less worn than QM F23725. The occlusal surface on M1 largely consists of dentine with most of the enamel having been lost. The crown perimeter is, however, surrounded by enamel. Wear is greatest on cusp apices and on the anterior and posterior lophs resulting in a 'bow-tie' pattern of wear on each moiety (Figures 3.3, 4.4). Wear is particularly concentrated on the lingual half of the occlusal surface. The lingual margin is relatively flat in lingual view on $\mathrm{M}^{1-2}\left(\mathrm{M}^{1-3}\right.$ on QM F23725) and lower in height relative to the buccal margin.

Enamel height is greatest on the lingual surface, particularly on the anterior moiety. Enamel height decreases at the lingual constriction. There is a slight increase in enamel height posterior to the lingual constriction on the posterior moiety. Enamel height decreases onto anterior and posterior surfaces from the lingual surface. On the buccal surface, enamel height is greatest beneath the paracone and metacone. Enamel height decreases towards the anterior and posterior edges of the tooth and at the buccal constriction. Enamel is thickest (between 0.4 to $0.7 \mathrm{~mm}$ thick) on the lingual side. Enamel appears to increase slightly in thickness between $\mathrm{M}^{1}$ and $\mathrm{M}^{3}$ on QM F23725. Vertical cracks in the enamel extend between the occlusal surface and the basal enamel-dentine junction (EDJ). There are a few small patches of what appear to be cementum on the lingual enamel. There are grooves on the outer enamel surface on the lingual side. These grooves are probably the remains of a complex cementumenamel junction (CEJ).

There are three roots: an anterolingual root, an anterobuccal root and a posterior root. The posterior root is buccolingually elongated so that it 
extends across the entire width of the posterior moiety. It has the widest buccolingual dimensions of all three roots. The anterobuccal root is the smallest of the three roots in all dimensions, although it is similar in anteroposterior width to the posterior root. In anterior view the anterobuccal root is located beneath the buccal half of the anterior moiety, and the anterolingual root is located beneath the lingual half of the anterior moiety. The anterolingual root is the largest of the three roots in overall volume and is widest anteroposteriorly. The convex lingual surface of the root is continuous with the convex lingual surface of the crown. The apex of the anterolingual root points slightly posteriorly (and buccally). The buccal constriction is continuous with the division between anterobuccal and posterior roots. The lingual constriction is approximately continuous with the division between anterolingual and posterior roots. There is a single apical foramen on the medial surface of each root.

$\mathbf{M} 1$. There is limited evidence regarding cusps on $M^{1}$. What can be inferred is based mainly on inflections of the buccal and anterior margins in occlusal view. This is best seen on QM F30339 (Figure 5.1). There is a distinct convexity located on the buccal margin in the stylar cusp C (StC) position on QM F30339. Anterior to this convexity the enamel margin faces anterolingually and is relatively flat. Immediately below this, the occlusal surface is slightly concave. A deep groove in the margin is present anterior to this (in profile view and extending posterobasally down the buccal enamel surface for a short distance as a concavity in the enamel). Immediately anterior to the groove the margin is inflected buccally again at a convexity that is similar in overall size to that adjacent to the constriction. The anterior convexity is located in the stylar cusp B (StB) position. The buccal surface is broadly convex for some distance basal (and posterobasally) to this.

Although the anterobuccal corner is damaged on all $\mathrm{M}^{1}$ specimens, there appears to be a parastylar region located anterior and slightly lingual to $\mathrm{StB}$. An enamel remnant is present on the occlusal surface of QM F23774 immediately posterolingual to the parastylar region. This remnant probably represents the anterior basin based on comparisons with the posterior molars on this specimen. An enamel remnant is also present adjacent to the buccal constriction on the occlusal surface of all $\mathrm{M}^{1} \mathrm{~s}$. This latter remnant probably represents the buccal end of the transverse valley. On QM F23725 and QM F30339 there is a minor groove on this latter enamel remnant that is located poste- rior to the constriction and approximately parallel to the buccal margin.

The lingual surface near the occlusal surface is shallowly inclined immediately anterior to the constriction relative to the rest of the lingual surface. In addition, the anterolingual root and the lingual surface directly occlusal to it project posterolingually (and basally) so that the root is almost directly lingual to the constriction at the alveolar margin. $\mathrm{M}^{1}$ tapers lingually slightly towards this point on the anterolingual root in occlusal view (particularly on QM F23774) and differs in this respect from $\mathrm{M}^{2-4}$. The lingual margin on the posterior half of the posterior moiety is relatively flat and faces posterolingually in occlusal view. The buccal constriction is relatively flat and wide (anteroposteriorly) in occlusal view. Immediately posterior to the buccal constriction the buccal surface is slightly flat or concave.

There is a significant decrease in enamel height on the lingual surface of $\mathrm{M}^{1}$ with enamel decreasing from a maximum on the anterior moiety to a minimum anterior to the midpoint on the posterior moiety. The EDJ is almost vertical across the constriction on QM F30339. The enamel height minimum is approximately coincident with, or slightly posterior to, the division between anterolingual and posterior roots. Posterior to this minimum, enamel height increases slightly before decreasing again onto the posterior surface.

The lingual constriction at the occlusal surface is located anterior to the enamel minimum and the division between the anterolingual and posterior roots. It is relatively deep close to the occlusal surface but fainter, basal to the occlusal surface. The constriction forms an angle of approximately $85^{\circ}$ to the occlusal surface and curves posteriorly and basally away from the occlusal surface as a semicontinuous and slightly sinuous groove.

Enamel height on the posterior surface is relatively small, increasing in height only slightly midway between enamel minima on posterobuccal and posterolingual 'corners'. The extensive enamel cover on the anterior half of the lingual surface extends onto the anterior surface. Enamel height decreases significantly over the anterolingual root on the anterior surface. The basal EDJ is approximately $80^{\circ}$ to the occlusal surface at this position. Enamel height is smallest just lingual to the division between anterobuccal and anterolingual roots. The basal EDJ is approximately horizontal between this point and the anterobuccal 'corner'. Enamel is thinnest on the anterior and posterior surfaces and at 
the constriction on the buccal surface where enamel height is smallest.

The secondary occlusal wear surface is deepest along an anteroposterior band that is closer to the lingual margin than the buccal margin on QM F23725. On QM F30339, wear is greatest near the centre of the occlusal surface and at the anterior and posterior margins midway between buccal and lingual surfaces. The occlusal dentine on QM F30339 undulates slightly. There are two faint ridges in the occlusal dentine that are orientated in an anterolingual-posterobuccal direction on QM F30339. The posterior ridge is restricted to the posterior moiety (Figure 5.1); the anterior ridge is fainter than the posterior ridge and extends between the notch on the anterior half of the buccal surface (near to where the paracone is on the posterior molars) and the anterolingual corner of the tooth. The occlusal dentine is broadly concave anterior and posterior to these 'pseudolophs'. Pulpal cornua are exposed at the occlusal surface on the anterior and posterior moieties of QM F30339.

All $\mathrm{M}^{1}$ root measurements were taken on $\mathrm{QM}$ F30339. Root dimensions were measured at the interradicular furcation. Anterobuccal and posterior roots are approximately $3 \mathrm{~mm}$ in anteroposterior width, and the anterolingual root is $3.5 \mathrm{~mm}$ in anteroposterior width. Buccolingual root width is $2.5 \mathrm{~mm}$ on the anterobuccal root, $4.5 \mathrm{~mm}$ on the posterior root and $3 \mathrm{~mm}$ on the anterolingual root. The posterior root has two tightly curved corners (buccal and lingual edges) and two broadly curved surfaces (anterior and posterior surfaces). In posterior view the buccal edge of the posterior root is almost vertical, and the lingual edge slopes buccally towards the root apex. In contrast, the anterolingual root does not taper significantly until $3 \mathrm{~mm}$ below the furcation at the position of the apical foramen. All three roots have single and simple apical foramen and a groove on the medial surface of the root adjacent to the interradicular furcation. The furcation between the anterolingual root and posterior root is slightly lower (further away from the occlusal surface) than that between the anterobuccal and posterior roots. The anterobuccal root has a fairly well developed ridge on its anterior surface.

$\mathbf{M}^{2}$. Similar to $\mathbf{M}^{1}$ except for the differences outlined below. The overall shape of $\mathrm{M}^{2}$ is more rectangular and bilobed than that of $\mathrm{M}^{1}$. The posterior half of the posterior moiety on the lingual side is distinctly flat and faces posterolingually. The lingual constriction is narrower than on $\mathrm{M}^{1}$; however, this may be related to greater wear on $\mathrm{M}^{1}$. In lingual view, the lingual constriction is continuous and better defined than on $\mathrm{M}^{1}$. It curves posteriorly and basally. A distinct parastyle is not obvious on $\mathrm{M}^{2}$ based on the occlusal outline. Distinct inflections in the StB and StC positions are not obvious on $\mathrm{M}^{2}$. The buccal margin may be slightly inflected lingually midway between the anterior edge of the tooth and the constriction, but this is not certainly the case. There may also be a slight lingual inflection midway along the buccal margin on the posterior moiety, but again this is not certain because both $\mathrm{M}^{2}$ specimens are slightly damaged.

The anterior and posterior basins are better preserved on $\mathrm{M}^{2}$ relative to $\mathrm{M}^{1}$, and they appear to be confluent with the crests which form the anterior and posterior margins of the tooth, respectively. The anterior and posterior crests are very narrow (anteroposteriorly). The anterior crest slopes anterobasally and the posterior cingulum slopes posterobasally. There may be a very minor crest between the respective basins and crests but it is not clear on either specimen. The posterior basin appears to be slightly lower (i.e., more basal) than the anterior basin. The anterior moiety projects higher above the alveolus than the posterior moiety, particularly on the buccal side. The roots below the level of the alveolus are not visible.

$M^{3}$. $M^{3}$ is similar to $M^{2}$ except as follows. There are no obvious stylar cusps; however, the buccal margin is worn on the posterior moiety of both specimens. In addition, there are faint grooves and bumps all over the occlusal surface and on the occlusal margins. Most of these are only just visible to the naked eye. The lingual constriction is even narrower than on $\mathrm{M}^{2}$ and remains very narrow away from the occlusal surface. The posterior half of the lingual margin on the posterior moiety is not as flat as it is on $\mathrm{M}^{2}$. There is a very distinct lingually- and basally-sloping wear facet on the lingual enamel at the constriction on QM F23725. The facet is widest (buccolingually) at or just anterior to the constriction and tapers anteriorly and posteriorly. The posterior basin is lower on the occlusal surface (more basal) than the anterior basin.

Greater detail is visible on the occlusal surface of $\mathrm{M}^{3}$ (particularly on QM F23774) than on $\mathrm{M}^{2}$. Grooves extend anterolingually and posterolingually from a point just lingual to where the anterior loph meets the buccal margin. The low point on the anterior and posterior lophs is approximately midway between buccal and lingual margins. The anterolingual groove extends into the anterior basin. The posterolingual groove extends as far as 
the transverse valley. Grooves extend anteriorly and posteriorly from the low point on both lophs. There may be a slight offset between these groves at the transverse valley on QM F23774 with the groove extending posteriorly from the anterior loph meeting the transverse valley buccal to the groove extending anteriorly from the posterior loph. In between these points within the transverse valley is the termination of a low ridge that extends posterobuccally from the approximate position of the protocone (not preserved on either specimen). The transverse valley is sinuous around this projection, and the buccal half of the valley is anterolingualposterobuccal in orientation. In contrast, the transverse valley on QM F23725 is relatively straight and buccolingual in orientation.

There is a relatively high crest that forms the buccal half of the anterior margin on QM F23774 (the occlusal surface of QM F23725 is more worn than that of QM F23774). The crest appears to decrease in height lingually towards the point where a groove that extends anteriorly from the anterior basin meets the anterior margin. In contrast to the anterior basin, the posterior basin is not bounded posteriorly by a crest. The buccal surface curves lingually immediately posterior to the probable location of the metacone on unworn specimens and is continuous with the posterior surface of the posterior loph. The posterior surface of the loph drops steeply posterobasally towards the posterior margin of the tooth. Faint grooves on the posterior surface of the loph extend posterobasally towards the posterior margin.

$\mathbf{M}^{4}$. The posterior moiety on $\mathrm{M}^{4}$ is around twothirds the width and length of the anterior moiety. It is also lower in occlusal height than the anterior moiety. The buccal and lingual constrictions are relatively shallow. The protocone is located on the anterolingual 'corner' of the occlusal surface; however, the paracone is located midway between the anterobuccal 'corner' and the constriction. The anterior loph is therefore orientated in a slightly anterolingual-posterobuccal direction. The anterior basin is wider (anteroposteriorly and buccolingually) and shallower than on $\mathrm{M}^{1-3}$. Grooves extend anterobuccally, anterolingually, posterobuccally and posterolingually from the anterior basin. The anterobuccal and anterolingual grooves extend as far as the anterior margin and bracket the anterior-most point on the tooth. Although poorly defined, this anterior 'projection' may be equivalent to the parastyle on $\mathrm{M}^{1}$. It is located buccal to the midpoint between buccal and lingual margins. The posterolingual groove meets the anterior loph at its lowest point (which is closer to the lingual margin than the buccal margin). The posterior continuation of this groove is approximately anteroposterior in orientation until it meets the transverse valley. The anterobuccal groove of the anterior basin meets the buccal half of the anterior loph lingual to the buccal margin. It appears to continue posterior to the loph as far as the transverse basin but is very faint.

The lingual surface posterior to the apex of the protocone is fairly convex and the enamel is relatively thick. In contrast, the lingual surface either side of the constriction is relatively thin and flat. Immediately anterior to the constriction, the lingual surface slopes lingually at a shallow angle for a short distance below the occlusal surface, whereas it dips more steeply posterior to the constriction. Away from the occlusal surface the lingual surface either side of the constriction is more convex. In lingual view, the lingual margin slopes basally towards the constriction to from a wide ' $v$ '.

The posterior loph is coincident with the posterior margin of the occlusal surface on $\mathrm{M}^{4}$. It is relatively straight and buccolingual in orientation. Immediately below the occlusal surface, the posterior surface slopes posterobasally at a slightly different angle to the rest of the posterior surface. Below this, the posterior edge of the tooth is strongly convex in occlusal view. The posterior margin of the occlusal surface is highest at the metaconule.

The metaconule is located on the posterolingual corner and is relatively low and almost indistinguishable from the posterior and lingual margins. It is roughly pyramidal. The posterior and lingual surfaces of the metaconule are steep and rounded. The anterobuccal face is almost triangular and is broad, flat and shallowly dipping. The metacone apex was probably located just anterior to the posterobuccal corner; however, the occlusal surface is worn at this position. The metacone was probably quite low and not particularly cuspate. The tips of all of the cusps are worn flat.

The transverse valley appears more bowl-like relative to the anterior molars and may be slightly shallower. The buccal half of the transverse valley bounds the anterior face of the metacone. The deepest point in the transverse valley is located just buccal to the lingual margin where the posterior continuation of the groove from the low point on the anterior loph meets it. A groove extends posterobuccally from this low in the transverse valley. It intersects the posterior margin just lingual to the posterobuccal corner adjacent to the 
metacone. This groove is probably equivalent to the groove that extends between the transverse valley and the low point on the posterior loph on $\mathrm{M}^{3}$. The buccal half of the posterior moiety is thus reduced in size relative to the lingual half on $\mathrm{M}^{4}$.

Enamel extends as far as the alveolar margin on the lingual and posterior surfaces of $\mathrm{M}^{4}$ on $\mathrm{QM}$ $\mathrm{F} 23774$. The enamel on the anterior surface is largely obscured by $\mathrm{M}^{3}$. Enamel height decreases on the anterior surface to a minimum just posterior to the anterobuccal corner of the tooth. Enamel height on the buccal surface increases posterior to this to a maximum located below (basal) and just posterior to the anterior loph. Enamel height increases slightly again posterior to this to a minimum just anterior to the buccal constriction. There is a slight increase in enamel height below the constriction. Enamel height increases posterior to the constriction and onto the posterior surface.

Lower Dentition. The molars are bilobed. Anterior and posterior moieties are fairly rounded in occlusal outline. Occlusal cusp morphology is not preserved on either lower molar specimen due to wear. The secondary occlusal wear surface consists of an enamel perimeter surrounding dentine. Enamel height is greatest, and is extensive, on the buccal surface but is fairly small (occlusobasally restricted) on all other surfaces. Enamel is also thickest on the buccal side.

There are two roots: an anterior root (located beneath the anterior moiety) and a posterior root (beneath the posterior moiety). The roots lean towards the posterior surface on QM F51404 (i.e., the root apices are closer to the posterior surface of the teeth than the anterior). The orientation of QM F23773 is unknown, but the posterior surface is tentatively identified as the one to which the roots lean on this latter specimen. Thin cementum covers the surfaces of the roots and extends over the enamel.

$\mathbf{M}_{\mathbf{1}}$. Anterior and posterior moieties are similar in anteroposterior length, although the posterior moiety is slightly longer than the anterior moiety, particularly on the buccal side (Figure 5.2). The anterior moiety is smaller in buccolingual width relative to the posterior moiety $(4.0 \mathrm{~mm}$ and $5.0 \mathrm{~mm}$, respectively). The anterior moiety narrows towards the anterior of the tooth and is particularly narrow towards the occlusal surface. In contrast, the posterior moiety is much wider and rounder. The posterior surface is broad and flat. The buccal surface is broadly convex and the lingual surface is relatively flat. The root surfaces are continuous with the crown surfaces. The crown is longest (antero- posteriorly) at the occlusal surface and shortest midway between the occlusal surface and the furcation between the roots. The tooth is widest (buccolingually) at or just below the level of the furcation (due to the curvature of the buccal surface).

The constriction between the moieties is broad and relatively flat on the lingual side and narrower and more 'pinched-in' on the buccal side in occlusal view. It is represented by a groove in the enamel that extends to the base of the enamel on the buccal surface and is approximately continuous with the furcation between the roots. On the lingual surface, the small enamel height and the poor condition of the lingual enamel on this specimen means that a distinct groove, if it was present, cannot be discerned below the occlusal surface.

Enamel surrounds the dentine of the occlusal wear surface of the tooth, although enamel height is variable. Enamel height is greatest on the buccal surface, where enamel extends as two narrow tracts down anterior and posterior roots. Enamel extends a significant distance below the furcation between the roots on this surface, particularly on the anterior root. Both enamel tracts taper towards the root apices. Enamel height decreases significantly between the roots from a height of at least 6 $\mathrm{mm}$ on the roots (the full extent being obscured by cementum) to $2.1 \mathrm{~mm}$ at the buccal constriction. Enamel height decreases onto anterior and posterior surfaces. Enamel is thickest on the buccal surface and is approximately $0.4 \mathrm{~mm}$ thick.

Enamel cover on the lingual surface is much less extensive than that on the buccal surface. Enamel height increases only slightly over anterior and posterior roots on the lingual surface. The base of the enamel remains a significant distance above the furcation between the roots on this side. Enamel height decreases slightly at the lingual constriction and onto the posterior surface. There is little change in enamel height towards the anterolingual 'corner' of the tooth except due to variations in height of the occlusal surface as a result of wear.

On the anterior surface, enamel height decreases from a maximum at the anterobuccal 'corner' to a minimum midway across the surface. The base of the enamel between these two points forms an angle of approximately $60^{\circ}$ to the occlusal surface. Lingual to the midpoint on the anterior surface, there is a very slight increase in enamel height before enamel height decreases again and continues to do so (at a very shallow angle) as far as the anterolingual 'corner'. There is a slight 
groove in the enamel on the anterior surface, just lingual to the anterobuccal 'corner'.

On the posterior surface, enamel height decreases at an angle of approximately $45^{\circ}$ to the occlusal surface from the posterobuccal 'corner' to a minimum that is lingual to the midpoint on the surface. Lingual to this, enamel height increases slightly towards the posterolingual 'corner' at an angle of about $40^{\circ}$. The base of the enamel either side of the minimum on this surface is broadly concave. The enamel height minimum is located just lingual to a topographic low (due to wear) on the posterior margin of the occlusal surface. The enamel on the posterior surface is flat as a result of tooth wear.

Original cusp detail is not preserved and has been replaced by a secondary wear surface characterised by an enamel perimeter and central dentine. The dentine is concavely worn with the central valley being anteroposterior in orientation. The deepest point on the occlusal surface is midway between buccal and lingual surfaces and slightly posterior to the constriction between the moieties. The dentine of the occlusal surface slopes towards the central valley at a slightly shallower angle on the buccal side relative to the lingual side. There is only a slight increase in the height of the occlusal dentine towards the posterior edge of the tooth, and the low point on the posterior perimeter is continuous with the central wear valley.

The central dentine is continuous with the 'push' side (inner or lingual edge; Koenigswald et al., 1994) of the enamel perimeter on the buccal side so that they form a continuous facet (although in places a small step between the two is developed). This facet between the enamel and dentine is buccolingually narrower either side of the buccal constriction, but increases in width towards the posterobuccal 'corner' of the tooth. The 'pull' side (outer or buccal edge; Koenigswald et al., 1994) of the buccal enamel on the posterior moiety is rounded (convex). There may be a thin facet adjacent to the constriction on this edge, but it is not clear. In buccal view, the occlusal profile is relatively flat and broadly concave across the buccal constriction and the midpoints on anterior and posterior moieties form topographic 'highs'. A low pseudoloph in the dentine of the occlusal surface extends lingually and slightly anteriorly from the posterior topographic high as far as the central wear valley.

The outer surface of the buccal enamel is irregular. This is probably a reflection of a complex enamel-cementum interface. The lingual enamel is thinner and more irregular in profile than the buccal enamel as a result of extensive chipping of the former. The lingual enamel is rounded where chipping has taken place. The posterior half of the lingual enamel on the posterior moiety is particularly chipped, and there is a relatively large triangular wedge of enamel missing midway across the lingual enamel on the anterior moiety. The occlusal dentine is continuous with the inner (buccal) edge of the lingual enamel.

The anterior half of the anterior moiety is dominated by a distinctive wear facet that slopes anteriorly, basally and slightly buccally. The facet extends across the enamel-dentine junction with the enamel and dentine being flush with one another. The facet itself appears slightly curved (anteroposteriorly) and has well-defined edges. The wear facet is bounded posteriorly by a ridge of dentine that forms a buccolingual topographic high. This ridge is rounded and is approximately parallel to the pseudoloph in the dentine of the posterior moiety. The occlusal surface immediately posterior to this ridge is concave and curves steeply basally towards the centre of the wear surface. There is a change in orientation and angle of this slope midway down.

The dentine ridge that forms the posterior boundary of the anterior facet meets another crest of dentine at its lingual edge. The latter crest extends posterolingually from this junction and forms the lingual boundary of the occlusal surface where the enamel edge has been extensively chipped. The anterior confluence of these two dentine crests is the highest point on the occlusal wear surface. If this point also formed a topographic high when the anterior lingual edge was bounded by enamel rather than dentine, there may well have been a concentration of occlusal pressure at this position. In addition, the high angle of the anterior wear facet compared to the rest of the wear surface indicates that multi-directional stresses would have been acting on the lingual enamel. It is therefore no surprise that failure of the lingual enamel occurred, such as that resulting in the large triangular gap in the enamel.

The furcation between the roots is slightly higher (more occlusal) on the lingual side relative to the buccal side. As a result, the furcation slopes away from the occlusal surface towards the lingual side. Both roots are wider buccolingually than anteroposteriorly and taper towards the lingual side. The medial surface of the roots is shallowly concave. The apical foramen is preserved on the posterior root, $1.9 \mathrm{~mm}$ occlusal to the root apex. 
The medial surface is deeply grooved between the apical foramen and the root apex.

$\mathbf{M}_{2} / \mathbf{M}_{3}$. QM F23773 is an $\mathbf{M}_{2}$ or $\mathbf{M}_{3}$ (Figure 5.3). It is similar to $M_{1}$, differing mainly in the greater similarity between anterior and posterior moieties and absence of the anterior wear facet and taper. The posterior moiety is slightly smaller in anteroposterior length than the anterior moiety, but is greater in buccolingual width. The tooth is longest at the occlusal surface and shortest (anteroposteriorly) at the level of the interradicular furcation. The constriction is well developed in occlusal view on buccal and lingual sides.

The anterior surface of the tooth is flat and slopes basally away from the occlusal surface. Posterior to the anterobuccal 'corner' of the tooth (on the buccal surface) is a groove that extends basally and slightly posteriorly away from the occlusal surface. The occlusal outline appears slightly 'pinched in' (buccolingually) between this groove and a similar position on the lingual margin. Immediately anterior to this, the anterobuccal and anterolingual 'corners' are relatively convex (in comparison with the posterobuccal and posterolingual corners) and emphasise the flat anterior edge. The anterior moiety is relatively symmetrical about the median anteroposterior plane of the tooth and differs from the posterior moiety in this respect. The posterior moiety is longer (anteroposteriorly) on the lingual side relative to the buccal side. The posterior-most point on the tooth is buccal to the midpoint on the posterior surface. Lingual to this, the posterior surface is relatively flat and faces slightly posterolingually. In contrast, the buccal half of the posterior surface is more broadly convex.

Enamel surrounds the occlusal surface and is thicker than on $M_{1}$, although this may be partially or wholly a result of differing amounts of occlusal wear between these tooth positions. Enamel is thickest (up to $0.5 \mathrm{~mm}$ ) on the buccal side and at the anterobuccal 'corner'. Enamel is extensive on the buccal surface, particularly over the roots. The enamel extends below the interradicular bifurcation onto the roots on the buccal side. There is a decrease in enamel height from the buccal surface onto anterior and posterior surfaces, with the greatest decrease being onto the anterior surface. Enamel height also decreases at the buccal constriction (above the interradicular bifurcation). Enamel height on the lingual surface is much less extensive. There is a slight increase in enamel height over the roots on the lingual surface. This is emphasised by the greater topographic height of the occlusal enamel at this position. Enamel height decreases at the lingual constriction and onto anterior and posterior surfaces.

On the anterior surface of the tooth, the basal EDJ is highest (closest to the occlusal surface) just buccal to the anterolingual 'corner'. Enamel height increases only slightly between this point and a point just lingual to the anterobuccal 'corner' of the tooth. Buccal to this, there is a significant increase in enamel height onto the buccal surface with the EDJ approaching vertical. There is also a slight increase in enamel height at the anterolingual 'corner'. Minimum enamel height is centrally located on the anterior surface due to a topographic low on the enamel perimeter at this position (i.e., in profile).

On the posterior surface, the basal EDJ is highest at the posterolingual 'corner'. Enamel height increases between this point and the posterobuccal 'corner', where the enamel is extensive. The basal EDJ slopes at an angle of approximately $30^{\circ}$ to the occlusal surface, although it increases in angle slightly towards the posterobuccal 'corner'. Minimum enamel height is located just lingual to the midpoint on the posterior surface due to a topographic low on the enamel perimeter at this position.

The central dentine of the occlusal surface is concave, being deepest along an anteroposterior axis located just lingual to the midpoint between buccal and lingual surfaces. This axis of greatest wear intersects the anterior and posterior edges of the occlusal surface at topographic lows. In anterior and posterior view, the occlusal surface ' $v$ 's to these low points. Occlusal wear on the anterior and posterior moieties resembles that on the posterior moiety of $M_{1}$. There is a small step between the central dentine and the buccal enamel (the dentine being worn lower) although dentine and enamel are nearly flush with one another. The buccal enamel is rounded on both 'push' and 'pull' sides with no clear well-defined facets. In buccal view, the buccal enamel is relatively flat at the occlusal surface although it is worn slightly lower at the constriction relative to the buccal margin anterior and posterior to it. In a similar manner to $\mathrm{M}_{1}$, the lingual enamel shows evidence of chipping with some of the fractured edges of the enamel being rounded. There are vertical cracks in the lingual enamel. The central dentine and lingual enamel are flush with one another.

Crown height on the buccal side (i.e., the distance between the interradicular bifurcation and the occlusal surface) is $5.6 \mathrm{~mm}$. Both roots are 8.4 $\mathrm{mm}$ in dorsoventral length between the interradicu- 
lar furcation and the root apices. The anterior root is $2.9 \mathrm{~mm}$ in anteroposterior width (on the buccal side) and $5.1 \mathrm{~mm}$ in buccolingual depth, measured just below the bifurcation. The posterior root is 3.2 $\mathrm{mm}$ in anteroposterior width and $5.5 \mathrm{~mm}$ in buccolingual depth. The apical foramen is located 3.7 $\mathrm{mm}$ above the root apex on the medial surface of the anterior root and $4.3 \mathrm{~mm}$ above the apex on the medial surface of the posterior root. The medial surface is grooved between the apical foramen and the apex on both roots.

\section{Comparisons}

Nimbavombatus boodjamullensis is a small, plesiomorphic vombatid. It is similar in size to the Pleistocene Warendja wakefieldi, previously the smallest vombatid known (Appendix 3). Using the regression equations in Myers (2001) both $N$. boodjamullensis and $W$. wakefieldi are estimated to have had a body mass between 6,000 and 9,000 $\mathrm{g}$ (using upper molar row length as a proxy, as well as $\mathrm{M}^{2}$ length in combination with upper molar row length). This is similar to slightly larger than a modern koala. In contrast, $R$. crowcrofti is estimated to have had a body mass of between 50,000 and $60,000 \mathrm{~g}$ (using lower molar length): an order of magnitude larger than that of $N$. boodjamullensis. The $N$. boodjamullensis specimens are unlikely to be juveniles because the roots are fully closed, the occlusal surfaces have undergone relatively large amounts of occlusal wear, and there are two similarly sized individuals from two different deposits at Riversleigh.

The combination of broad inflections in enamel height around the cheek teeth, thickened enamel on the lingual surface of the upper molars and buccal surface of the lower molars, simple $\mathrm{P}^{3}$ with small parastyle, crest-like parametacone and small posterolingual crest and valley identify $N$. boodjamullensis as a vombatid. The combination of rooted cheek teeth, with cusp detail preserved in the adult dentition, presence of a $\mathrm{C}^{1}$ and $\mathrm{I}^{2}$ and/or $\mathrm{I}^{3}$, minor inflections in enamel height around the cheek teeth (compared to other vombatids) identify $N$. boodjamullensis as the most plesiomorphic vombatid known. Estimated to be early Miocene in age, it is also one of the oldest vombatids known. The only other vombatid described from deposits older than late Miocene is Rhizophascolonus crowcrofti, which is known from isolated teeth from early to middle Miocene deposits of South Australia and Queensland (Archer et al., 1997). The molars of $R$. crowcrofti are similar to those of $N$. boodjamullensis; however, the inflections in enamel height are much better developed in $R$. crowcrofti forming a pattern of enamel and dentine tracts around the tooth that broadly correspond to those of hypselodont wombats (particularly species of Warendja). Similarities between $R$. crowcrofti and $N$. boodjamullensis include the presence of a wider anterior moiety below the occlusal surface on $\mathrm{M}^{1}$ (partly due to a projecting anterolingual root), the decrease in lingual enamel height between the anterior and posterior moiety on $\mathrm{M}^{1}$ and the constriction between the anterior and posterior moieties sloping posteriorly away from the occlusal surface in lingual view on the upper molars. In addition, $N$. boodjamullensis and $R$. crowcrofti are the only vombatids with rooted cheek teeth.

The unworn occlusal morphology of the cheek teeth is not known for any extinct vombatid with the exception of Warendja encorensis (Brewer et al., 2007). This is because cusp details are only preserved in very young individuals in wombats, and that wombats are relatively rare components of most faunas. In $W$. encorensis, interpretation of the cusps on the two juvenile molar specimens available is confounded by uncertainty regarding tooth position. Comparisons of cusp details with N. boodjamullensis are thus largely limited to the modern taxa, V. ursinus and L. latifrons (Appendix 4).

Nimbavombatus boodjamullensis molars are bunodont with stylar cusps reduced or absent, and paracone and metacone located on the buccal margin. This contrasts with the upper molars of $V$. ursinus and $L$. latifrons as well as other non-lophodont vombatiform marsupials where stylar cusps are expressed quite strongly on the upper molars. It is possible that the simplified, bunodont occlusal morphology on $N$. boodjamullensis is apomorphic for this taxon.

In addition to the characters listed above, the upper molars of $N$. boodjamullensis also differ from those of $V$. ursinus in the absence of a well-developed parastyle on $\mathrm{M}^{2-4}$, in the lack of expansion of the anterior parastylar region and the absence of crenulations in the enamel (in the form of minor cusps and crests) that can be seen on the unworn occlusal surface of $V$. ursinus molars (Appendix 4). They differ from those of $L$. latifrons in that the parastyle is better developed on $\mathrm{M}^{1}$ and in the anterior location of the metacone relative to $L$. latifrons. The molars of $N$. boodjamullensis differ from those of $V$. ursinus and $L$. latifrons in the rectangular-shaped occlusal outline (in occlusal view).

Upper molars of $N$. boodjamullensis differ from those of $W$. encorensis in the absence of a high anterior margin, presence of relatively low 
1

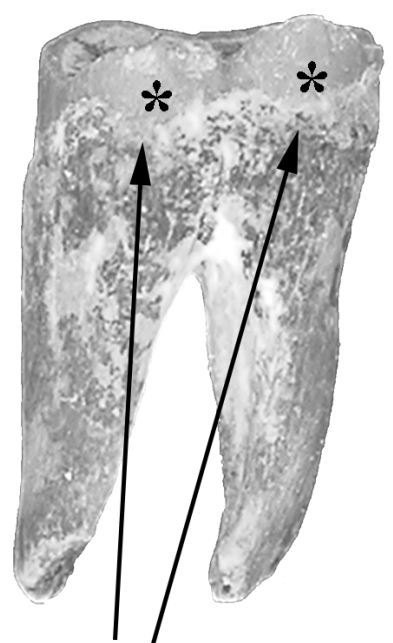

Base of enamel obscured by cementum
2

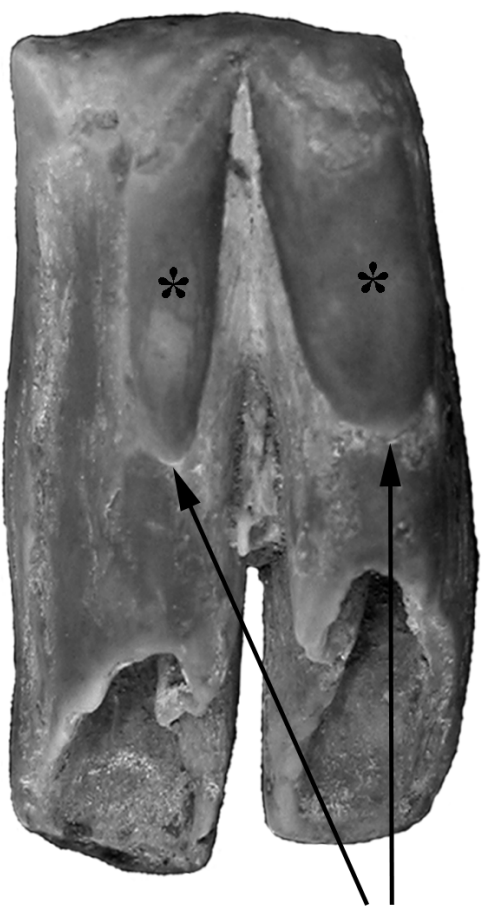

Base of enamel tracts
3 Cementum

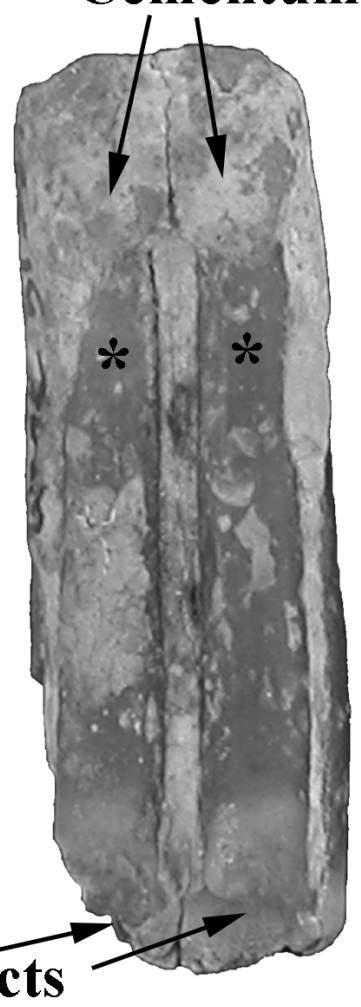

FIGURE 6. Lingual view of lower molars to show presence of enamel tracts (indicated by asterisks). 1, Nimbavombatus boodjamullensis. 2, Rhizophascolonus crowcrofti. 3, Warendja encorensis.

bunodont cusps, presence of a simple, non-bifurcated medial crest connecting the main cusps in each moiety and the greater similarity in height between anterior and posterior moieties.

The overall pattern of inflections in enamel height around the cheek teeth is similar in N. boodjamullensis and $R$. crowcrofti. Enamel height minima tend to be relatively broad on $N$. boodjamullensis in comparison to $R$. crowcrofti and the inflections in the enamel height tend to be less sharp. Enamel minima and maxima in N. boodjamullensis and $R$. crowcrofti broadly correspond to the pattern of dentine tracts and enamel tracts in species of Warendja (Figure 6). The relative widths of the dentine tracts in the latter are more similar to $R$. crowcrofti than N. boodjamullensis.

Enamel extends below the level of the interradicular furcation and onto the surface of the roots on the lingual side of the upper molars, buccal side of the lower molars and on the anterior root of $\mathrm{P}^{3}$ in $N$. boodjamullensis and $R$. crowcrofti. Enamel height on the lingual surface is markedly smaller on the posterior moiety relative to the anterior moiety on $\mathrm{M}^{1}$ in both $N$. boodjamullensis and $R$. crowcrofti. We have not observed a dentine tract at this position in other vombatids. The difference in enamel height between anterior and posterior moieties on the lingual surface is not as pronounced towards the posterior end of the molar row in N. boodjamullensis and $R$. crowcrofti.

The molars of $N$. boodjamullensis, $R$. crowcrofti and species of Warendja differ from all other vombatids in the shape of the occlusal outline (in occlusal view), being only slightly inflected at the lingual constriction on the upper molars and at the buccal constriction on the lower molars. The extreme inflections on the lingual side of the uppers and buccal side of the lowers of all other vombatids are not seen in any other Australian marsupial. The relatively shallow depth of these inflections in $N$. boodjamullensis, $R$. crowcrofti and species of Warendja is therefore symplesiomorphic.

Rhizophascolonus crowcrofti and N. boodjamullensis are the only vombatids for which the anterior moiety on $\mathrm{M}^{1}$ is wider than the posterior 
moiety. The similarity between $\mathrm{M}^{1}$ in $\mathrm{N}$. boodjamullensis and $R$. crowcrofti is probably partly due to the projecting lingual root. The difference in width between the moieties is least at the occlusal surface and increases away from it (as a result of the projecting lingual root). However, the relative width of the moieties is variable between specimens and is dependent on where the measurement is taken for both taxa. The narrow occlusal surface of the anterior moiety of $\mathrm{M}^{1}$ in pouch young specimens of $V$. ursinus and $L$. latifrons is very distinctive (particularly in L. latifrons) and is not shared by $N$. boodjamullensis.

In contrast to the narrow anterior moiety on $\mathrm{M}^{2}$ of $V$. ursinus and $L$. latifrons, the anterior moiety on $\mathrm{M}^{2}$ or $\mathrm{M}^{3}$ is usually the widest part of the molar row in N. boodjamullensis. $\mathrm{M}^{4}$ in $N$. boodjamullensis and $R$. crowcrofti is generally narrower than $\mathrm{M}^{4}$ in $V$. ursinus and $L$. latifrons. It is similar in relative width to Phascolonus gigas. All vombatids have a narrower posterior moiety than anterior moiety on $\mathrm{M}^{4}$.

The $\mathrm{P}^{3}$ of $N$. boodamullensis is similar to that of $V$. ursinus and $L$. latifrons in that it is dominated by the parametacone crest with a poorly developed parastylar region and a low-lying posterolingual crest. It differs from them in that the paracone dominates the occlusal surface, and the metacone is much more crest-like than the paracone. There is an inflection of the anterolingual surface just posterior to the parastyle on $\mathrm{P}^{3}$ in $\mathrm{N}$. boodjamullensis that is in a similar position to the distinctive anterolingual groove on the adult $\mathrm{P}^{3} \mathrm{~S}$ of $V$. ursinus and $L$. latifrons.

The $M_{1}$ of $N$. boodjamullensis resembles that of all other wombats (with the exception of some specimens of $P$. gigas and Ramsayia lemleyi) in that the anterior moiety is narrower than the posterior moiety. The anterior moiety on $M_{1}$ forms a topographic high just posterior to the anterior edge of the tooth in $N$. boodjamullensis. This wear profile is also seen in early wear stages in V. ursinus and $L$. latifrons $\mathrm{M}_{1} \mathrm{~s}$ and is located at the position of the protolophid. In Warendja, the anterior topographic high on $M_{1}$ is coincident with the anterior surface of the tooth rather than just posterior to it. It is possible that this is related to a much reduced or absent anterior cingular region and paracristid in Warendja relative to the other taxa.

The anterior ventral root of the zygomatic arch is located above the anterior moiety of $\mathrm{M}^{2}$ in $N$. boodjamullensis. In $W$. wakefieldi it is located above the contact between $\mathrm{M}^{2}$ and $\mathrm{M}^{3}$ (Flannery and Pledge, 1987; Brewer, 2007). The ventral root slopes laterally as a shelf in $N$. boodjamullensis, whereas in $W$. wakefieldi it forms a relatively shallow convexity for about $7 \mathrm{~mm}$ before flaring laterally at the maxillojugal suture. There is a dishshaped infraorbital fossa in $W$. wakefieldi. In contrast, in $N$. boodjamullensis this area is relatively flat and slightly convex. The height between the alveolar margin and the dorsal surface of the zygomatic arch is much greater in $W$. wakefieldi than $N$. boodjamullensis. The posterobasal slope of the dorsal surface of the alveolar process (maxillary shelf) is also greater in $W$. wakefieldi as a result of the presence of hypselodont teeth in the latter that decrease in occlusobasal length from $\mathrm{M}^{1}$ to $\mathrm{M}^{4}$.

The anterior margin of the maxillary vacuity is located medial to the posterior moiety of $\mathrm{M}^{2}$ in both $N$. boodjamullensis and $W$. wakefieldi. The width of the palate between the median palatine suture and the alveolar margin at $\mathrm{M}^{1}$ and $\mathrm{M}^{2}$ is similar in $W$. wakefieldi and N. boodjamullensis (relative to overall size).

\section{RESULTS OF THE PHYLOGENETIC ANALYSIS}

Three minimally parsimonious trees were generated when all taxa were included in the analysis. All trees had 229 steps, a Consistency Index (Cl) of 0.6445 , a Retention Index (RI) of 0.7070 and Rescaled Consistency Index (RC) of 0.4755 . The only thing that changed regarding the topologies of these trees was the position of Marada arcanum (strict consensus tree shown in Figure 7.1). Hence, this taxon was excluded and the analysis was re-run. The result was a single most parsimonious tree with the same topology as the previous trees, but without $M$. arcanum (Figure 7.2). This tree has 228 steps and $\mathrm{Cl}=0.6476, \mathrm{RI}=$ 0.7028 and $\mathrm{RC}=0.4747$. Unambiguous apomorphies are given in Appendix 5 .

Bootstrap support was high (98\%) for a monophyletic ingroup and for Diprotodontoidea (i.e., Diprotodontidae + Palorchestidae). Support was moderate $(78 \%)$ for a monophyletic Vombatidae with three unambiguous apomorphies supporting this group: pattern of enamel/dentine tracts on molars and premolars and the absence of a masseteric process. Support was poor $(<60 \%)$ for the arrangement of the other taxa. Within Vombatidae there is moderate support $(76 \%)$ for monophyly of hypselodont wombats based on three unambiguous apomorphies: loss of $\mathrm{C}^{1}$, presence of hypselodont cheek teeth and the extension of enamel tracts down outer surfaces of the cheek teeth. Nimbavombatus boodjamullensis and $R$. crowcrofti 
1

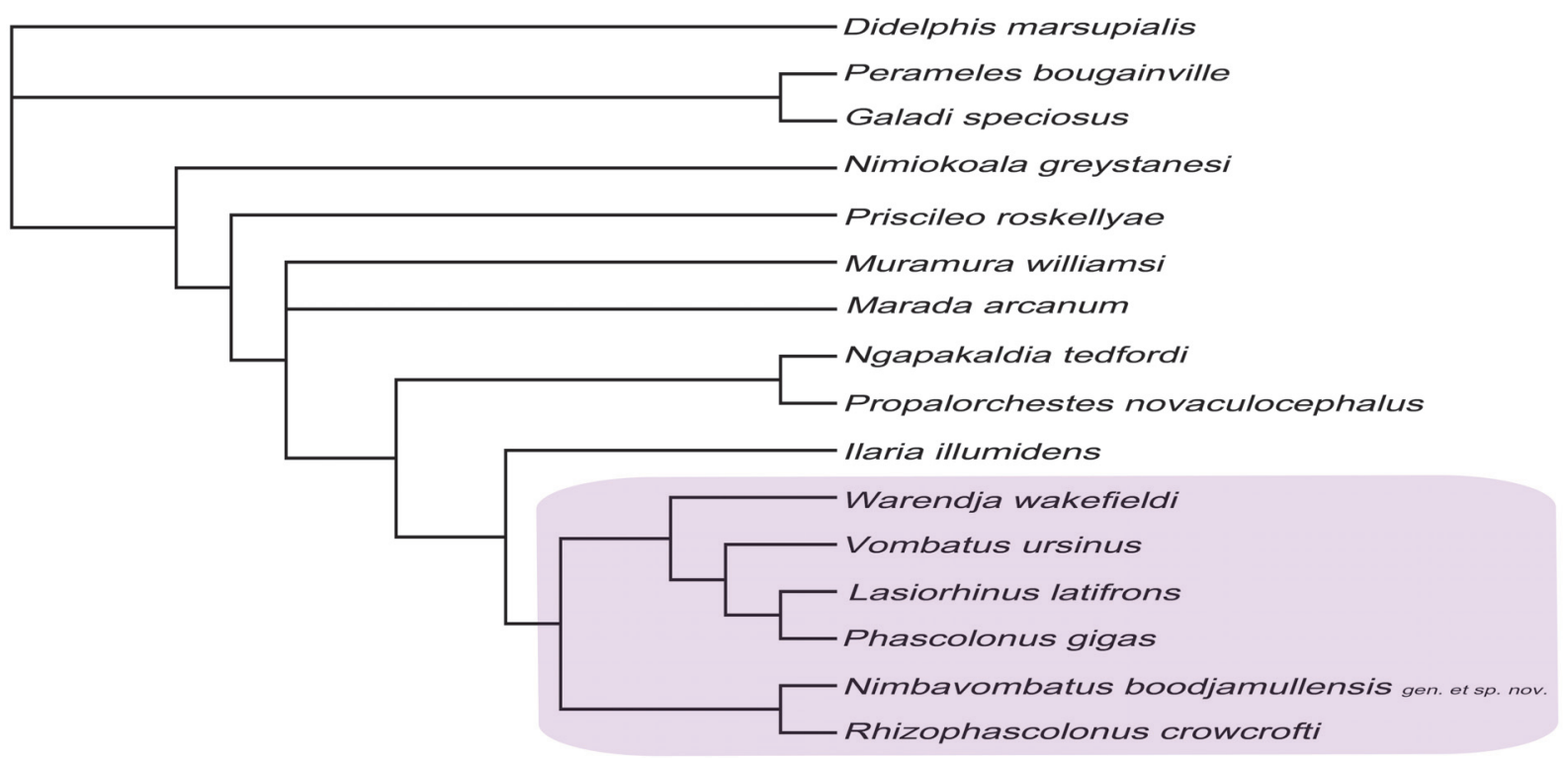

$\mathbf{2}$

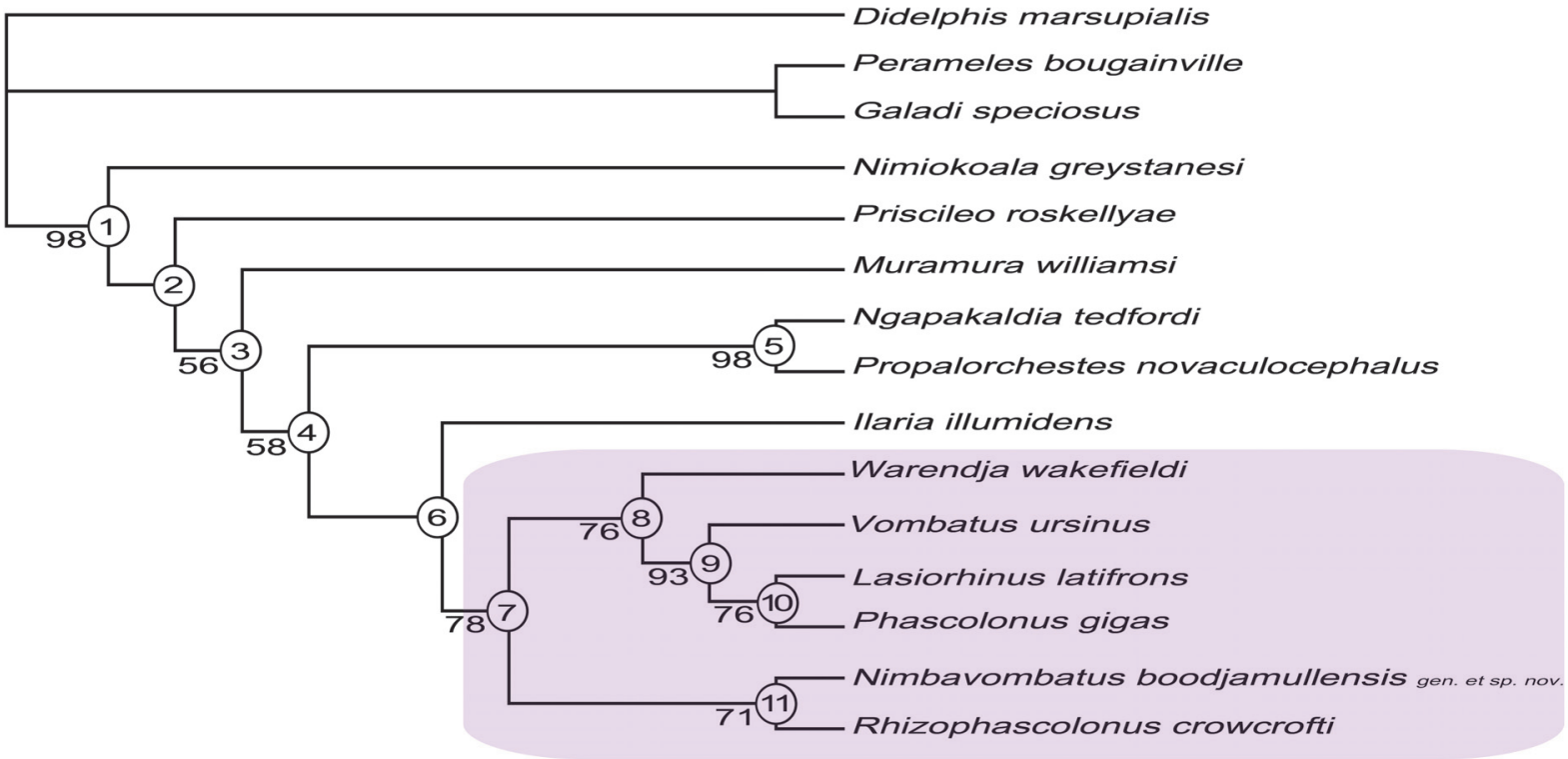

FIGURE 7. 1, Strict consensus tree for parsimony analysis including Marada arcanum. 2, Bootstrap support for single most parsimonious tree from analysis excluding Marada arcanum (see text for details). Vombatidae indicated in purple.

form a sister group to the hypselodont wombats, but are united based on a single unambiguous apomorphy: enamel height on posterior moiety of $\mathrm{M}^{1}$ smaller than on anterior moiety in lingual view.

\section{DISCUSSION}

Regardless of whether $N$. boodjamullensis and $R$. crowcrofti are directly ancestral to the hypselodont wombats, these taxa do shed light on possible intermediate stages in the evolution of the tooth morphology (and related cranial and mandibular adaptations) of modern wombats.

\section{Evolution of Enamel and Dentine Tracts}

The evolution of dentine tracts based on inflections in enamel height was documented in geomyoid rodents (Rensberger, 1971, 1975), and a 
similar mechanism appears to be responsible for the evolution of dentine tracts in wombats. Under this model, small inflections in enamel height around the perimeter of the tooth become exaggerated over time. In taxa that have hypselodont teeth, these inflections can be observed on the occlusal enamel cap of very young individuals. This enamel cap is worn away early in ontogeny and enamel height minima are then represented by dentine tracts. Using the terminology of Tummers and Thesleff (2003), a switch to a 'root fate' occurs early in tooth development at those positions represented by dentine tracts (i.e., enamel production ceases), whilst this switch does not occur where enamel tracts are present.

The inflections in enamel height and thickness around the molars of $N$. boodjamullensis and $R$. crowcrofti broadly correspond to the pattern of enamel and dentine tracts present around the molars in both species of Warendja, with the inflections in enamel height being more pronounced in species of Warendja than R. crowcrofti, which in turn are more pronounced than in $N$. boodjamullensis (Figure 6). Species of Warendja, R. crowcrofti and $N$. boodjamullensis all possess two enamel tracts on the leading edges of the molars (buccal surface of the upper molars and lingual surface of the lower molars). They differ in this respect from all other wombats, where enamel is absent on the leading edge of adult molars (except as aberrations), although enamel tracts can sometimes be seen in juvenile specimens of $V$. ursinus and $L$. latifrons (e.g., NMV C10928). If we imagine an evolutionary sequence starting with $N$. boodjamullensis, passing through $R$. crowcrofti and then Warendja and finishing with $V$. ursinus/L. latifrons we have a plausible model for the evolution of the modern pattern of enamel around the perimeter of wombat molars. This is not to suggest that these species are directly ancestral to one another. However, this sequence does present, on a simplistic level, a working hypothesis that can be tested as additional vombatid specimens come to light.

If we tentatively accept the above model, $N$. boodjamullensis has already advanced from the plesiomorphic state (represented by non-vombatid vombatiform marsupials) in that trailing edge enamel is thicker than leading edge enamel and is more extensive, extending further down and across the trailing surface. In contrast, the leading edge enamel is relatively thin and restricted and forms two broad inflections in enamel height: one on the anterior moiety and one on the posterior moiety. Enamel height and thickness is least at the con- striction between the moieties on the leading edge and on anterior and posterior surfaces. Moving from $N$. boodjamullensis to $R$. crowcrofti and species of Warendja, differences in enamel height and thickness as well as in width of the tracts become more pronounced over time. Leading edge enamel is eventually lost and enamel becomes continuous across the trailing surface. Traces of this evolutionary history can be traced in the inflections in enamel height on the enamel caps of juvenile molars of $V$. ursinus and $L$. latifrons.

\section{Mastication in Wombats}

Jaw movement during the power stroke in mastication is wholly transverse in $V$. ursinus and L. latifrons (Ferreira et al., 1989; Murray, 1998; Crompton et al., 2008b), and this was probably also the case in Ramsayia, Phascolonus and "Phascolomys" due to the similarity in molar morphology between these taxa and extant wombats. The lower molars on the working side of the jaw move medially and slightly anteriorly across the upper molars in a single movement. Enamel is restricted to the trailing edge of the molars (lingual surface of the upper molars and buccal surface of the lower molars) as well as those parts of the anterior and posterior surfaces which form part of the enamel cutting edge.

Enamel is thickest and most extensive on the trailing edge of the molars in N. boodjamullensis. This is confirmed by the presence of a step between the central dentine and trailing edge (Greaves, 1973; Rensberger, 1973; Costa and Greaves, 1981). In contrast, the enamel on the leading edge (buccal surface of the upper molars and lingual surface of the lower molars) is always flush with the central dentine. Pseudolophs in the central dentine on QM F30339 (see description) confirm that overall movement of the lower jaw on the working side during the power stroke in N. boodjamullensis was anteromedial. In contrast to hypselodont wombats with the exception of Warendja, the topography of the worn occlusal surface is not flat but dips steeply between the leading edge and the centre of the occlusal surface in anterior and posterior view. The presence of highangled wear facets on the trailing edge of the molars (Figure 4.3) suggest intimate contact between leading and trailing edges of molars in the opposing jaw in a plane that is at a sharp angle to the top of the trailing edge enamel. Together these observations suggest that the power stroke in $N$. boodjamullensis consisted of two phases: an initial dorsal (orthal) movement (accounting for the 
angled wear facets and the steeply dipping occlusal surface on the leading side) followed by a predominantly transverse movement of the jaw (the flatter trailing side). Together, these are superimposed on the overall anteromedial movement of the jaw during the power stroke (Figure 8).

A two phase power stroke is seen in macropodids (Sanson, 1980; Crompton et al., 2008a) and Phascolarctos cinereus (Crompton et al, 2010), although these are not equivalent to phases I and II of placental mammals (Crompton et al., 2008a, 2010). In both macropodids and $P$. cinereus, there is an initial orthal component to the power stroke (phase I), followed by a predominantly transverse movement of the lower jaw (phase II). These observations fit the hypothesis that a two-phase power stroke was symplesiomorphic for Diprotodontia and Vombatiformes and that the specialised dental adaptations seen by the various vombatiform families were accompanied by modifications of this two-phase power stroke, with vombatids elaborating phase II. Elaboration of phase II and eventual suppression of phase I in hypselodont vombatids, is likely to be associated with loss of the leading edge enamel on the molars.

The presence of an orthal component to the power stroke is consistent with the skull and jaw architecture of $N$. boodjamullensis as well as $W$. wakefieldi (the only other plesiomorphic wombat for which we have cranial remains). The skull of $W$. wakefieldi is high and narrow with a weak sagittal crest and is unlike the broad flat cranium of modern wombats (Pledge, 1992). The masseteric and pterygoid fossae of the mandible are both relatively shallow. The corresponding area on the skull for insertion of the masseter is relatively small in both $W$. wakefieldi and $N$. boodjamullensis in comparison to modern wombats. The angle of the ascending ramus of the mandible is shallower than in modern vombatids. These features are indicative of a relatively greater importance of the temporalis muscle in mastication compared to modern vombatids, as was first suggested by Hope and Wilkinson (1982) for W. wakefieldi.

The trailing edge enamel on the molars of $N$. boodjamullensis and Warendja probably differed in function to that of modern wombats. In modern wombats, the trailing edge enamel is much thinner and forms angled and sharp shearing crests. In contrast, the trailing edge enamel on the molars of the Warendja and N. boodjamullensis is relatively thick and poorly curved and probably functioned in more of a grinding capacity. In N. boodjamullensis, it is possible that shearing was accomplished by the leading enamel (and anterior dentition). Hence, in addition to a shift from a two-phase power stroke to a one-phase power stroke, there may have been a shift between shearing being accomplished in phase I to it occurring at the end of phase II. The hypothesis presented here applies primarily to teeth that show moderate to advanced wear (in order to be comparable with hypselodont wombat teeth) and would need to be tested using methods such as microwear analysis. The bunodont morphology of mildly worn teeth of $N$. boodjamullensis suggests that crushing and grinding actions may have been of greater importance than in more worn teeth.

\section{CONCLUSIONS}

Nimbavombatus boodjamullensis is a rare, plesiomorphic wombat with a molar cusp morphology that differs from extant wombats in the poor development of stylar and accessory cusps and ridges. It is contemporaneous with the only other wombat known from deposits older than $10 \mathrm{Ma}$, Rhizophascolonus crowcrofti. Although both taxa are found in fossil deposits of the Riversleigh World Area in northwestern Queensland, they are not found in the same deposits (refer to Travouillon et al., 2006 for an overview of the Oligo-Miocene deposits in the Riversleigh World Heritage Area). They differ in details of the cheek tooth enamel and in overall size, with $N$. boodjamullensis being significantly smaller than $R$. crowcrofti. Hence, although both taxa are rare components of a rainforest environment, they almost certainly occupied different niches. A phylogenetic analysis confirmed that $N$. boodjamullensis is a member of a monophyletic Vombatidae, but grouped $N$. boodjamullensis and $R$. crowcrofti together as a sister group to the hypselodont wombats. This sister relationship was based on a single dental character state shared by $N$. boodjamullensis and $R$. crowcrofti. Inflections in enamel height on the molars of $N$. boodjamullensis and $R$. crowcrofti can be correlated with the pattern of enamel and dentine tracts seen on the molars of hypselodont wombats, particularly species of Warendja. It is concluded that increasing emphasis on the trailing edge enamel / second phase of the power stroke in wombats drove many of the obvious dental shape changes from the early to mid-Miocene to the present day.

\section{ACKNOWLEDGEMENTS}

Support for research at Riversleigh has come from the Australian Research Council (LP0989969, 


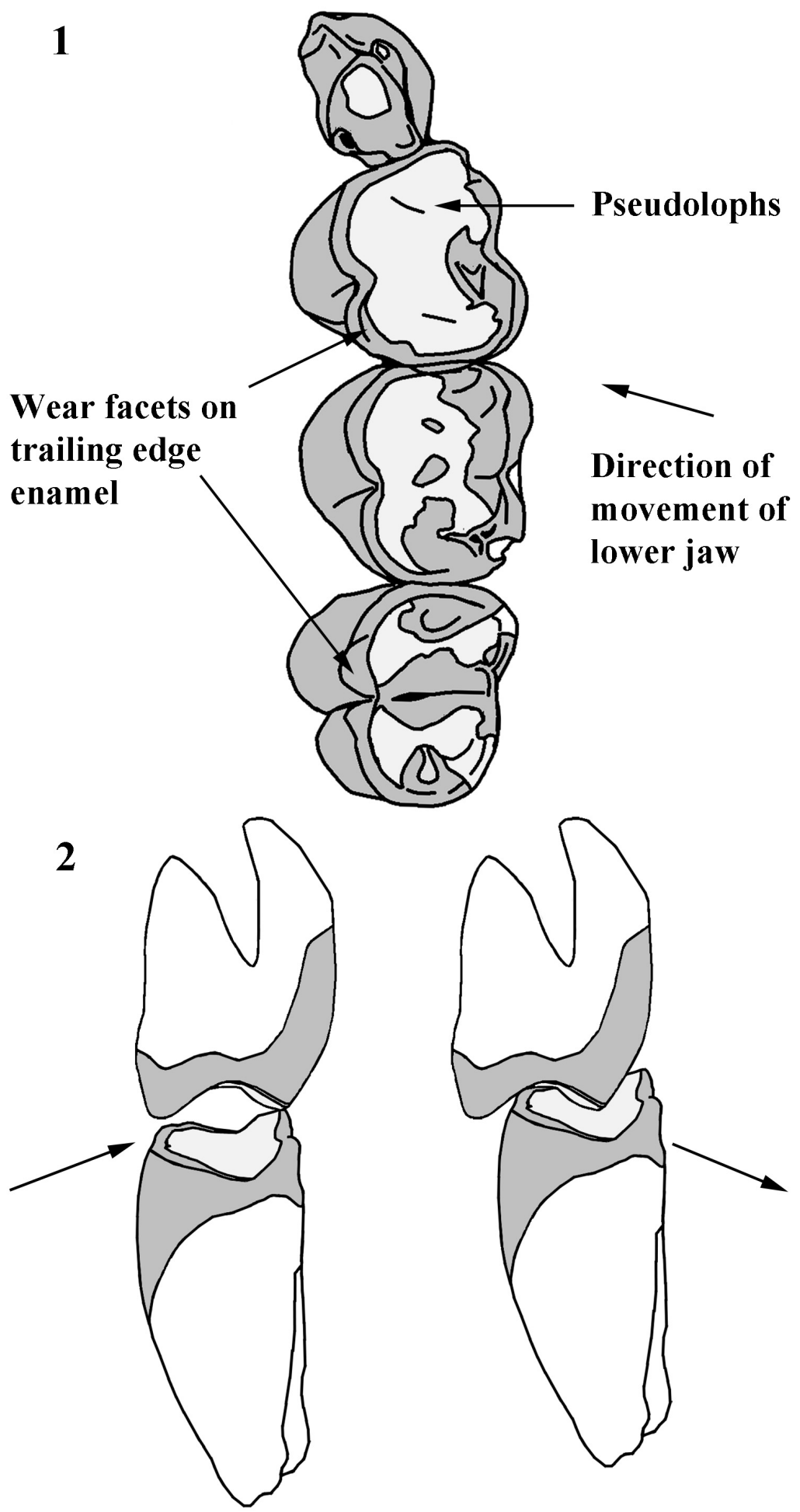

FIGURE 8. Jaw movement during the power stroke in Nimbavombatus boodjamullensis. 1, Evidence of jaw movement on the surface of the cheek teeth. 2, Movement of the lower jaw during Phase I (left) and Phase II (right) of the power stroke. 
LP100200486, DP1094569 and DP130100197 grants to M. Archer, S.J. Hand and K.H. Black at the University of New South Wales); XSTRATA Community Partnership Program (North Queensland); the University of New South Wales; $P$. Creaser and the CREATE Fund; the Queensland Parks and Wildlife Service; Environment Australia; the Queensland Museum; the Riversleigh Society, Inc.; Outback at Isa; Mount Isa City Council; and private supporters including K. and M. Pettit, E. Clark, M. Beavis and M. Dickson. Assistance in the field has come from many hundreds of volunteers as well as staff and postgraduate students of the University of New South Wales. Support for this project has come from a Sylvester Bradley Award (to P. Brewer) from the Palaeontological Association. Many thanks to J. Louys and A.W. Crompton who reviewed earlier drafts of this manuscript, to K.H. Black for her assistance with the phylogenetic analysis and J.J. Hooker for useful discussions.

\section{REFERENCES}

Andrews, P., Lord, J.M., and Nesbit Evans, E.M. 1979. Patterns of ecological diversity in fossil and mammalian faunas. Biological Journal of the Linnean Society, 11:177-205

Aplin, K.P. and Archer, M. 1987. Recent advances in marsupial systematics with a new syncretic classification, p. xv-Ixxii. In Archer, M. (ed.), Possums and Opossums: Studies in Evolution. Surrey Beatty \& Sons Pty Limited, Chipping Norton, England.

Archer, M. 1984. The Australian marsupial radiation, p. 633-808. In Archer, M. and Clayton, G. (eds.), Vertebrate Zoogeography \& Evolution in Australasia (Animals in Space \& Time). Hesperian Press, Carlisle, Western Australia.

Archer, M., Godthelp, H., Hand, S.J., and Megirian, D. 1989. Fossil mammals of Riversleigh, northwestern Queensland: preliminary overview of biostratigraphy, correlation and environmental change. Australian Zoologist, 25:29-65.

Archer, M., Hand, S.J., Godthelp, H., and Creaser, P. 1997. Correlation of the Cainozoic sediments of the Riversleigh World Heritage fossil property, Queensland, Australia, pp. 131-152. In Aguiler, J.P., Legendre, S., and Michaux, J. (eds.), Actes du Congres BiochroM '97. Memoires et Travaux de I'Institut de Montpellier de l'Ecole Pratique des Hautes Etudes, 21.

Archer, M., Arena, R., Bassarova, M., Black, K., Brammall, J., Cooke, B., Creaser, P., Crosby, K., Gillespie, A., Godthelp, H., Gott, M., Hand, S.J., Kear, B., Krikmann, A., Mackness, B., Muirhead, J., Musser, A., Myers, T., Pledge, N., Wang, Y., and Wroe, S. 1999. The evolutionary history and diversity of Australian mammals. Australian Mammalogy, 21:1-45.
Arena, D.A. 2004. The geological history and development of the terrain at the Riversleigh World Heritage Area during the middle tertiary. Unpublished PhD Thesis, University of New South Wales, Sydney, Australia.

Beck, R.M.D. 2008. A dated phylogeny of marsupials using a molecular supermatrix and multiple fossil constraints. Journal of Mammalogy, 89:175-189.

Black, K. 2007. Maradidae: a new family of vombatomorphian marsupial from the late Oligocene of Riversleigh, northwestern Queensland. Alcheringa, 31(1):17-32.

Black, K. and Archer, M. 1997. Nimiokoala gen. nov. (Marsupialia, Phascolarctidae) from Riversleigh, northwestern Queensland, with a revision of Litokoala. Memoirs of the Queensland Museum, 41:209228.

Black, K.H., Archer, M., and Hand, S.J. 2012. New Tertiary koala (Marsupialia, Phascolarctidae) from Riversleigh, Australia, with a revision of phascolarctid phylogenetics, paleoecology, and paleobiodiversity. Journal of Vertebrate Paleontology, 32:125-138.

Black, K.H., Archer, M., Hand, S.J., and Godthelp, H. 2013. Revision in the diprotodontid marsupial genus Neohelos: systematics and biostratigraphy. Acta Palaeontologica Polonica, 58(4):679-706.

Brewer, P. 2007. New record of Warendja wakefieldi (Vombatidae; Marsupialia) from Wombeyan Caves, New South Wales. Alcheringa, 31:153-171.

Brewer, P., Archer, M., and Hand, S. 2008. Additional specimens of the oldest wombat Rhizophascolonus crowcrofti (Vombatidae; Marsupialia) from the Wipajiri Formation, South Australia: an intermediate morphology? Journal of Vertebrate Paleontology, 28:1144-1148.

Brewer, P., Archer, M., Hand, S., and Godthelp, H. 2007. A new species of the wombat Warendja from late Miocene deposits at Riversleigh, north-west Queensland, Australia. Palaeontology, 50(4):811828.

Burnett, G.T. 1830. Illustrations of the Quadrupeda, or quadrupeds; being an arrangement of the true fourfooted beasts indicated in outline. Quarterly Journal of Science, Literature and Art, 28:336-353.

Calendini, F. and Martin J.F. 2005. PaupUP v1.0.3.1 A free graphical frontend for Paup* Dos software.

Costa, R.L., Jr., and Greaves, W.S. 1981. Experimentally produced tooth wear facets and the direction of jaw motion. Journal of Paleontology, 55:635-638.

Creaser, P. 1997. Oligo-Miocene sediments of Riversleigh: the potential significance of topography. Memoirs of the Queensland Museum, 41:303-314.

Crompton, A.W., Owerkowicz, T., and Skinner, J. 2010. Masticatory motor pattern in the koala (Phascolarctos cinereus): a comparison of jaw movements in marsupial and placental herbivores. Journal of Experimental Zoology A: Ecological Genetics and Physiology 313:564-578. 
Crompton, A.W., Lieberman, D.E., Owerkowicz, T., Baudinette, R.V., and Skinner, J. 2008b. Motor control of masticatory movements in the Southern hairynosed wombat (Lasiorhinus latifrons), p. 83-111. In Vinyard, C.J., Ravosa, M.J., Wall, C.E. (eds.), Primate Craniofacial Function and Biology. Springer, New York.

Crompton, A.W., Barnet, J., Lieberman, D.E., Owerkowicz, T., Skinner, J., and Baudinette, R.V. 2008a. Control of jaw movements in two species of macropodines (Macropus eugenii and Macropus rufus). Comparative Biochemistry and Physiology - Part A: Molecular \& Integrative Physiology, 150:109-123.

Dawson, L. 1981. The status of the taxa of extinct giant wombats (Vombatidae: Marsupialia), and a consideration of vombatid phylogeny. Australian Mammalogy, 4:65-79.

Dawson, L. 1983a. The taxonomic status of small fossil wombats (Vombatidae: Marsupialia) from Quaternary deposits, and of related modern wombats. Proceedings of the Linnean Society of New South Wales, 107:101-123.

Dawson, L. 1983b. On the uncertain generic status and phylogenetic relationships of the large extinct vombatid species Phascolomys medius Owen, 1872 (Marsupialia: Vombatidae). Australian Mammalogy, 6:5-13.

Ferreira, J.M., Phakey, P.P., and Palamara, J. 1989. Electron microscopic investigation relating the occlusal morphology to the underlying enamel structure of molar teeth of the wombat (Vombatus ursinus). Journal of Morphology, 200:141-149.

Flannery, T.F. and Pledge, N.S. 1987. Specimens of Warendja wakefieldi (Vombatidae: Marsupialia) from the Pleistocene of South Australia, p. 365-368. In Archer, M. (ed.), Possums and Opossums: Studies in Evolution. Surrey Beatty \& Sons Pty Limited, Chipping Norton, England.

Flower, W.H. 1867. On the Development and Succession of the Teeth in the Marsupialia. Philosophical Transactions of the Royal Society of London, 157:631-641.

Frewein, J., Habel, R.E., and Sack, W.O. 1994. Nomina Anatomica Veterinaria. World Association of Veterinary Anatomists, Ithaca, New York.

Greaves, W.S. 1973. The inference of jaw motion from wear facets. Journal of Paleontology, 47:1000-1001.

Hernández Fernández, M., Alberdi, M.T., Azanza, B., Montoya, P., Morales, J., Nieto, M., and Peláez-Campomanes, P. 2006. Identification problems of arid environments in the Neogene-Quaternary mammal record of Spain. Journal of Arid Environments, 66:585-608.

Hope, J.H.W. and Wilkinson, H.E. 1982. Warendja wakefieldi, a new genus of wombat (Maruspialia, Vombatidae) from Pleistocene sediments in McEacherns Cave, western Victoria. Memoirs of the National Museum of Victoria, 43:109-121.
Horovitz, I., and Sánchez-Villagra, M.R. 2003. A morphological analysis of marsupial mammal higher-level phylogenetic relationships. Cladistics, 19:181-212.

Koenigswald, W.v., Sander, P.M., Leite, M.B., Mors, T., and Santel, W. 1994. Functional symmetries in the schmelzmuster and morphology of rootless rodent molars. Zoological Journal of the Linnean Society, 110:141-179.

Louys, J. 2004. Cranial descriptions of archaic koalas and an examination of vombatiform phylogeny based on cranial characters. Unpublished Honours thesis, University of New South Wales, Sydney, Australia.

Louys, J., Aplin, K., Beck, R.M.D., and Archer, M. 2009. Cranial anatomy of Oligo-Miocene koalas (Diprotodontia: Phascolarctidae): stages in the evolution of an extreme leaf-eating specialization. Journal of Vertebrate Paleontology, 29:981-992.

Luckett, W.P. 1993. An ontogenetic assessment of dental homologies in therian mammals, p. 182-204. In Szalay, F.S., Novacek, M.J., and McKenna, M.C. (eds.), Mammal Phylogeny: Mesozoic Differentiation, Multituberculates, Monotremes, Early Therians and Marsupials. Springer-Verlag, New York.

Luo, Z.-X., Kielan-Jaworowska, Z., and Cifelli, R.L. 2002. In quest for a phylogeny of Mesozoic mammals. Acta Palaeontologica Polonica, 47:1-78.

Marshall, L.G., Case, A., and Woodburne, M.O. 1990. Phylogenetic relationships of the families of marsupials, p. 433-502. In Genoways, H.H. (ed.), Current Mammalogy. Plenum Press, New York.

Merrilees, D. 1967. Cranial and mandibular characters of modern mainland wombats (Marsupialia, Vombatidae) from a palaeontological viewpoint, and their bearing on the fossils called Phascolomys parvus by Owen (1872). Records of the South Australian Museum, 15:398-418.

Mones, A. 1982. An equivocal nomenclature: what means hypsodonty? Paläontologische Zeitschrift, 56:107-111.

Munson, C.J. 1992. Postcranial descriptions of Ilaria and Ngapakaldia (Vombatiformes, Marsupialia) and the phylogeny of the vombatiforms based on postcranial morphology. University of California Publications in Zoology, 125. University of California Press, Berkeley, California.

Murray, P. 1986. Propalorchestes novaculacephalus gen. et sp. nov., a new palorchestid (Diprotodontoidea: Marsupialia) from the middle Miocene Camfield Beds, Northern Territory, Australia. The Beagle, Records of the Northern Territory Museum of Arts and Sciences, 3:195-211.

Murray, P.F. 1998. Palaeontology and palaeobiology of wombats, p. 1-33. In Wells, R.T. and Pridmore, P.A. (eds.), Wombats. Gaughwin \& J. Ferris, Surrey Beatty \& Sons, in association with The Royal Zoological Society of South Australia Inc., Chipping Norton. 
Myers, T. and Archer, M. 1997. Kuterintja ngama (Marsupialia, Ilariidae): a revised systematic analysis based on material from the late Oligocene of Riversleigh, northwestern Queensland. Memoirs of the Queensland Museum, 41(2)379-392.

Myers, T., Crosby, K., Archer, M., and Tyler, M. 2001. The Encore Local Fauna, a Late Miocene assemblage from Riversleigh, northwestern Queensland. Memoir of the Association of Australasian Palaeontologists, 25:147-154.

Owen, R. 1866. Comparative Anatomy and Physiology of Vertebrates. Longmans Green, London.

Pledge, N.S. 1992. The weird wonderful wombat Warendja wakefieldi Hope \& Wilkinson. The Beagle, Records of the Northern Territory Museum of Arts and Sciences, 9:111-114.

Reig, O.A., Kirsch, J.A.W., and Marshall, L.G. 1987. Systematic relationships of the living and the neocenozoic American "opossum-like" marsupials (Suborder Didelphimorphia), with comments on the classification of these and of the Cretaceous and Paleogene New World and European metatherians, p. 1-89. In Archer, M. (ed.), Possums and Opossums: Studies in Evolution. Surrey Beatty and Sons Pty. Ltd., Chipping Norton, New South Wales.

Rensberger, J.M. 1971. Entoptychine pocket gophers(Mammalia, Geomyoidea) of the Early Miocene John Day Formation, Oregon. University of California Publications in Geological Sciences, 90:1-163.

Rensberger, J.M. 1973. An occlusion model for mastication and dental wear in herbivorous mammals. Journal of Paleontology, 47:515-528.

Rensberger, J.M. 1975. Function in the cheek tooth evolution of some hypsodont geomyid rodents. Journal of Paleontology, 49:10-22.

Rougier, G.W., Wible, J.R., and Novacek, M.J. 1998. Implications of Deltatheridium specimens for early marsupial history. Nature, 396:459-463.

Sánchez-Villagra, M.R. and Wible, J.R. 2002. Patterns of evolutionary transformation in the petrosal bone and some basicranial features in marsupial mammals, with special reference to didelphids. Journal of Zoological Systematics and Evolutionary Research, 40:26-45.

Sanson, G.D. 1980. The morphology and occlusion of the molariform cheek teeth in some Macropodinae (Marsupialia: Macropodidae). Australian Journal of Zoology, 28:341-365.

Scott, G.G., Richardson, K.C., and Groves, C.P. 1988. Osteological Differences of the Skulls of Lasiorhinus latifrons Owen, 1845 and Vombatus ursinus Shaw, 1800 (Marsupialia, Vombatidae). Australian Journal of Zoology, 36(5):599-609.

Springer, M.S., Kirsch, J.A.W., and Case, J.A. 1997. The chronicle of marsupial evolution, p. 129-161. In Givnish, T.J. and Sytsma, K.J. (eds.), Molecular EvoIution and Adaptive Radiation. Cambridge, University Press, Cambridge, U.K.
Stirton, R.A., Tedford, R.H., and Woodburne, M.O. 1967. A new Tertiary formation and fauna from the Tirari Desert, South Australia. Records of the South Australian Museum, 15:427-461.

Swofford, D.L. 2002. PAUP*. Phylogenetic Analysis Using Parimony ( ${ }^{*}$ and other methods). Sinauer Associates, Sunderland, Massachusetts.

Tedford, R.H. 2002. The basicranium of the giant wombat Phascolonus gigas Owen (Vombatidae: Marsupialia) and its significance in phylogeny, p. 39-47. In Emery, R.J. (ed.), Cenozoic Mammals of Land and Sea: Tributes to the Career of Clayton E. Ray. Smithsonian Institution Press.

Travouillon, K.J., Archer, M., Hand, S.J., and Godthelp, H. 2006. Multivariate analyses of Cenozoic mammalian faunas from Riversleigh, northwestern Queensland. Alcheringa Special Issue, 1:323-349.

Travouillon, K.J., Gurovich, Y., Beck, R.M.D., and Muirhead, J. 2010. An exceptionally well-preserved shortsnouted bandicoot (Marsupialia: Peramelemorphia) from Riversleigh's Oligo-Miocene deposits, northwestern Queensland, Australia. Journal of Vertebrate Paleontology, 30:5, 1528-1546.

Tummers, M. and Thesleff, I. 2003. Root or crown: a developmental choice orchestrated by the differential regulation of the epithelial stem cell niche in the tooth of two rodent species. Development, 130:1049-1057.

Weisbecker, V. and Archer, M. 2008. Parallel evolution of hand anatomy in kangaroos and vombatiform marsupials: functional and evolutionary implications. Palaeontology, 51(2):321-338.

Weisbecker, V. and Sánchez-Villagra, M.R. 2006. Carpal evolution in diprotodontian marsupials. Zoological Journal of the Linnean Society, 146:369-384.

Woodburne, M.O. 1984. Families of marsupials: relationships, evolution and biogeography, p. 48-71. In Broadhead, T.W. (ed.), Mammals: Notes for a Short Course, Studies in Geology (Vol. 8). University of Tennessee, Knoxsville.

Woodburne, M.O., Tedford, R.H., Archer, M., and Pledge, N.S. 1987. Madakoala, a new genus and two species of Miocene koalas (Marsupialia: Phascolarctidae) from South Australia and a new species of Perikoala, p. 293-317. In Archer, M. (ed.), Possums and Opossums: Studies in Evolution. Surrey Beatty and Sons Pty. Ltd., Chipping Norton, New South Wales.

Woodhead, J., Hand, S., Archer, M., Graham, I., Sniderman, K., Arena, D.A., Black, K., Godthelp, H., Creaser, P., and Price, E. 2014. Developing a radiometrically-dated chronologic sequence for Neogene biotic change in Australia, from the Riversleigh World Heritage Area of Queensland. Gondwana Research, doi 10.1016/j.gr.2014.10.004. 
Wroe, S., Brammall, J.R., and Cooke, B.N. 1998. The skull of Ekaltadeta ima (Marsupialia, Hypsiprymnodontidae?): an analysis of some marsupial cranial features and a re-investigation of propleopine phylogeny, with notes on the inference of carnivory in mammals. Journal of Paleontology, 72:738-751.
Wroe, S., Ebach, M., Ahyong, S., Muizon, C., and Muirhead, J. 2000. Cladistic analysis of Dasyuromorphian (Marsupialia) phylogeny using cranial and dental characters. Journal of Mammalogy, 81:1008-1024. 


\section{APPENDIX 1.}

List of characters used in the phylogenetic analysis. Characters indicated by an asterisk are ordered in the analysis.

1.* Number of upper incisors (modified from Springer et al., 1997, Rougier et al., 1998, Wroe et al., 2000, Horovitz and SánchezVillagra, 2003 and Black et al., 2012): (0) More than three; (1) Two or Three; (2) One.

2. Size of $\mathrm{I}^{1}$ relative to $\mathrm{I}^{2}$ (Black et al., 2012): (0) Equal or similar in length; (1) Large, elongate.

3. Upper canine (modified from Springer et al., 1997, Horovitz and Sánchez-Villagra, 2003 by Black et al., 2012): (0) Present; (1) Absent or vestigal.

4. $\quad$ Number of upper premolars (Black et al., 2012): (0) Three; (1) Two; (2) One.

5. Posterobuccal cusp on $\mathrm{P}^{3}$ (Woodburne et al., 1987; Black and Archer, 1997; Myers and Archer, 1997; Black et al., 2012): (0) Absent; (1) Present.

6. Enamel extending down the buccal surface of $\mathrm{P}^{3}$ and onto the root: (0) Absent; (1) Present.

7. $\quad$ Size of $\mathrm{P}^{3}$ relative to $\mathrm{M}^{1}$ (modified from Black and Archer, 1997 and Black et al., 2012): (0) $P^{3}$ length greater than $M^{1}$ length; (1) $P^{3}$ length less than or equal to $\mathrm{M}^{1}$ length; (2) $\mathrm{P}^{3}$ length less than or equal to $80 \%$ of $\mathrm{M}^{1}$ length.

8. $\quad$ Molar morphology (Black et al., 2012): (0) Tribosphenic; (1) Selenodont; (2) Semilophodont/bunodont; (3) Lophodont but stylar cusps still evident on lophs; (4) Fully lophodont.

9. Hypselodont cheek teeth (modified from Murray, 1998; Black et al., 2012): (0) Absent; (1) Present.

10. Enamel noticeably thicker on trailing edge (lingual surface on upper molars and buccal surface on lower molars) relative to leading edge of molars (buccal surface on upper molars and lingual surface on lower molars): (0) Absent; (1) Present.

11.* Presence of enamel tracts that extends down the lingual surface of upper molars and buccal surface of lower molars: (0)

12. Anteriorly concave lower / anteriorly convex upper molar lophs (Black et al., 2012): (0) Absent; (1) Present.

13. $M^{1}$ with decrease in enamel height on lingual surface at constriction or just posterior to this: (0) Absent; (1) Present.

14. * Parastyle development on $\mathrm{M}^{1}$ (Black and Archer, 1997; Black et al., 2012): (0) Absent/small; (1) Moderately developed expansion of anterobuccal tooth corner; (2) Large, cuspate and pyramidal.

15. Presence of a cusp on posterobuccal side of $\mathrm{M}^{1}$ (and occasionally $\mathrm{M}^{2}$ ) in position of St-E: (0) Absent; (1) Present.

16. $\quad$ St-C larger and better developed than St-B on $\mathrm{M}^{2}$ : (0) Absent; (1) Similar in size; (2) Present.

17. Presence of crest connecting paracone to St-B on M2: (0) Absent; (1) Present.

18. $\quad$ Separation of stylar cusps $C$ and $D$ (modified from Myers and Archer, 1997 and Black et al., 2012): (0) Close together; (1) Separated; (2) Separated by a large trough.

19. Postprotocrista (Archer, 1984; Black et al., 2012): (0) Present; (1) Absent.

20. $M^{2}$ width of anterior moiety versus tooth length (modified from Springer et al., 1997; Horovitz and Sánchez-Villagra, 2003 by Black et al., 2012): (0) $M^{2}$ longer than wide; (1) $M^{2}$ width is greater or equal to length.

21. $\mathrm{M}^{4}$ metaconule (Black et al., 2012): (0) Absent / significantly reduced and retracted towards posterior cingulum; (1) Distinct / cuspate.

22. Posteriorly increasing (upper) molar gradient (modified from Black, 2007 and Black et al., 2012): (0) Absent, $M^{4} / M^{1}$ is less than or equal to 1 ; (1) Present, $M^{4} / M^{1}$ is greater than 1. 
23.* Number of lower incisors (modified from Springer et al., 1997, Rougier et al., 1998, Wroe et al., 2000, Luo et al., 2002, Horovitz and Sánchez-Villagra, 2003 and Black et al., 2012): (0) Two or more; (1) One.

24. Inclination angle of $\mathrm{I}_{1}$ (Marshall et al., 1990; Springer et al., 1997; Horovitz and Sánchez-Villagra, 2003; Black, 2007; Black et al., 2012): (0) High (greater or equal to 30 degrees); (1) Low (less than 30 degrees).

25. Development of paraconid and paracristid on $\mathrm{M}_{1}$ (modified from Myers and Archer, 1997, Horovitz and Sánchez-Villagra, 2003 by Black, 2007; Black et al., 2012): (0) Paraconid present and paracristid welldeveloped; (1) Paraconid weak or absent; paracristid present and distinct; (2) Paraconid and paracristid absent.

26. Protostylid on $\mathrm{M}_{1}$ (Woodburne et al. 1987; Black and Archer 1997; Myers and Archer 1997; Springer et al. 1997; Black 2007): (0) Absent; (1) Present.

27. Cristid obliqua (modified from Black, 2007 and Black et al., 2012): (0) Well-developed, meets or approaches postprotocristid lingual to horizontal tooth midline; (1) Well-developed, meets or approaches postprotocristid buccal to horizontal tooth midline; (2) Weak / absent.

28. Distinct and separate paraconid on $\mathrm{M}_{2-4}$ : (0) Absent; (1) Present.

29. Paraconid located on lingual side of tooth on $\mathrm{M}_{2-3}$ (or preprotocristid / paracristid terminates on lingual side of tooth): (0) Present; (1) Absent, located close to midline or buccal side of tooth.

30. Paraconid connected to protoconid via crest on $\mathrm{M}_{2-3}$ (or well-developed preprotocristid / paracristid): (0) Present; (1) Absent.

31. Presence of a crest connecting entoconid and hypoconid: (0) Absent; (1) Present.

32. Incisive foramen posterior (modified from Dawson, 1983b; Murray, 1998; Tedford, 2002): (0) Absent; (1) Present, the incisive foramina lie posteriorly, just anterior to $P^{3}$, in a deep pocket at the rear of the diastema. The posterior position of the foramina correspondingly displaces the premaxillary-maxillary suture to a position just anterior to the cheek tooth.

33. Lateral edge of palate emarginated from $\mathrm{I}^{1}$ to $P^{3}$ in ventral view (modified from Tedford, 2002): (0) Absent; (1) Present.

34. Palate width opposite first molar (ventral view) (Merrilees, 1967; Scott et al., 1988): (0) Narrow, less than buccolingual width of $\mathrm{M}^{1}$; (1) Wide, equal to or greater than buccolingual width of $\mathrm{M}^{1}$.

35. Median premaxillary process (Tedford, 2002): (0) Absent; (1) Well-developed or present as a low spine at the midline dorsal surface of the premaxilla.

36. $\quad$ Position of infraorbital foramen: (0) Close to level of alveolar process; (1) Approximately midway between dorsal surface of skull and alveolar process; (2) Closer to dorsal surface of skull than alveolar process of tooth row.

37.* Posterior palatal vacuities (maxillopalatine vacuity) (modified from Archer, 1984, Reig et al., 1987, Rougier et al., 1998, Wroe et al., 2000, Horovitz and Sánchez-Villagra, 2003 and Black et al., 2012): (0) Extends anteriorly to a point anterior of $\mathrm{M}^{3}$; (1) Confined within palate, opposite $\mathrm{M}^{3-4}$; (2) Absent.

38.* Nasal aperture retracted beyond incisor arcade (modified from Black et al., 2012): (0) Absent or just posterior to incisor arcade; (1) Retracted to above diastema (or level of premaxillary-maxillary suture); (2) Retracted to above cheek tooth row.

39. Nasomaxillary suture length relative to nasopremaxillary suture length (dorsal view) (Scott et al., 1988): (0) Nearly same or greater; (1) Far less than nasopremaxillary suture length.

40. Separate left and right parietal ridges along entire length of parietal bone: (0) Absent; (1) Present.

41.* Masseteric process (Wroe et al., 1998; modified version in Black et al., 2012): (0) Absent; (1) Short; (2) Elongate.

42. Dorsoventral position of ventral extent of anterior zygomatic root (relative to the cheek tooth row): (0) Close to level of alveolar process; (1) Distant to alveolar process. 
43. Anteroposterior position of ventral extent of anterior zygomatic root (relative to the cheek tooth row): (0) Above $\mathrm{M}^{3}$ or $\mathrm{M}^{4}$; (1) Above junction between $\mathrm{M}^{2}$ and $\mathrm{M}^{3} ;$ (2) Above $\mathrm{M}^{2}$; (3) At junction between $\mathrm{M}^{1}$ and $\mathrm{M}^{2}$ or anterior to $\mathrm{M}^{2}$.

44. Infraorbital shelf (Black et al., 2012): (0) Well-developed; (1) Weak.

45. Postglenoid process (Springer et al., 1997; Horovitz and Sánchez-Villagra, 2003; modified version in Black et al., 2012): (0) Present; (1) Absent.

46. Tympanic cavity roof elements (modified from Travoullion et al., 2010 and Black et al., 2012): (0) Alisphenoid (no squamosal contribution); (1) Alisphenoid and squamosal; (2) Squamosal (no alisphenoid contribution).

47. Tympanic floor elements (Black et al., 2012): (0) Alisphenoid; (1) Alisphenoid and squamosal; (2) Squamosal.

48. $\quad$ Alisphenoid tympanic wing (modified from Springer et al., 1997, Wroe et al., 1998, Horovitz and Sánchez-Villagra, 2003 and Black et al., 2012): (0) Absent; (1) Short; (2) Moderate to elongate, extends under periotic.

49. Epitympanic fenestra developed in postglenoid cavity (Black et al., 2012): (0) Absent; (1) Present.

50. Non-auditory sinuses (Murray, 1986; Black et al., 2012): (0) Absent; (1) Present.

51. Posterior epitympanic fossa (modified from Murray, 1986; modified from Black et al., 2012): (0) Absent / weak; (1) Moderate to deep.

52.* Postglenoid cavity / epitympanic fossa (modified from Murray, 1998, Tedford, 2002, Louys, 2004 and Black et al., 2012):

(0) Absent; (1) Present, but shallow; (2) Present and moderately extensive / deep.

53.* Rostral tympanic process of periotic (Rougier et al., 1998; Sánchez -Villagra and Wible, 2002; Horovitz and Sánchez-Villagra, 2003 modified version; Black et al., 2012): (0) Strong; (1) Weak / absent.

54. Posterior parietal width (Black et al., 2012): (0) Broad; (1) Narrow.

55. Interparietal (Louys et al., 2009; Black et al., 2012): (0) Present; (1) Absent.
56. Narrow mastoid strip on occiput (Murray, 1986; Black et al., 2012): (0) Absent; (1) Present.

57. Ventrolaterally flared mastoid process on occiput (Murray 1986; Black et al., 2012):

(0) Absent; (1) Present.

58. $\quad$ Length of articular surface (mandible) relative to length of cheek tooth row (modified from Scott et al., 1988): (0) Short, ratio of 0.4 or less; (1) Medium, ratio of 0.5 to 0.6 ; (2) Long, ratio of 0.7 or greater.

59.* Forward extent of ectalveolar groove of mandible (Dawson, 1983a): (0) Posterior of $M_{4}$; (1) Junction between $M_{3}$ and $M_{4}$ to mid $\mathrm{M}_{4}$; (2) Adjacent to $\mathrm{M}_{3}$.

60. $\quad$ Depth of masseteric fossa (mandible) (Merrilees, 1967; Scott et al., 1988): (0) Shallow to medium; (1) Deep; (2) Very deep.

61. Angle of the anterior border of the ascending ramus (mandible) (modified from Hope and Wilkinson, 1982; Black, 2007; Black et al., 2012): (0) $<70^{\circ}$; (1) $>$ or $=70^{\circ}$.

62.* $\quad$ Posterior extent of mandibular symphysis (mandible) (Black, 2007; Black et al., 2012): (0) Anterior to $\mathrm{P}_{3}$; (1) Below $\mathrm{P}_{3}$; (2) Below $\mathrm{M}_{1}$; (3) Below $\mathrm{M}_{2-3}$.

63.* Diastema length between $\mathrm{I}_{1}$ and $\mathrm{P}_{3}$ (modified from Black, 2007 and Black et al., 2012): (0) < 30\% horizontal ramus length; (1) Approximately $30 \%$ horizontal ramus length; (2) > 30\% horizontal ramus length.

64. Distance between anterior edge of $\mathrm{P}_{3}$ and posterior edge of $\mathrm{M}_{4}$ relative to length of horizontal ramus (mandible) (Black et al., 2012): (0) > 60\%; (1) < or $=60 \%$.

65. Flared masseteric eminences (mandible) (Murray, 1998; Black et al., 2012): (0) Absent / weak; (1) Moderately to strongly flared.

66. Masseteric foramen (Black, 2007; Black et al., 2012): (0) Absent; (1) Present.

67. Fused mandibular symphysis: (0) Absent; (1) Present.

68. Cervical vertebrae: combined length of C3C7 divided by width of C7 (Munson, 1992): (0) > 1.0 (long neck); (1) < 1.0 (short neck).

69. Humerus: max. width across distal end divided by length (Munson, 1992): (0) < or $=0.3 ;(1)>0.3$. 
70. Humerus: deltoid ridge (Munson, 1992): (0) Has no lateral overhang, or a very minor one; (1) Has a large flaring overhang.

71. ${ }^{*} \quad$ Humerus: deltoid tuberosity (modified from Scott and Richardson, 1988): (0) Angle between deltoid and pectoral crests $<30^{\circ}$; (1) Angle between $30^{\circ}$ and $40^{\circ}$; (2) Angle > $40^{\circ}$.

72. Ulna: anteroposterior thickness at semilunar notch divided by bone length (modified from Munson, 1992): (0) < or =0.10; (1) > 0.10 .

73. Ulna: length of olecranon process divided by bone length (Munson, 1992): (0) < 0.20; (1) $>$ or $=0.20$.

74. Ulna: max. anteroposterior thickness at coronoid process divided by bone length (Munson, 1992): (0) <0.2; (1) > or $=0.2$.

75. Radius: length (Munson, 1992): (0) > length of humerus; (1) $<$ or = length of humerus.

76. Radius: anteroposterior thickness of distal end divided by bone length (Munson, 1992): $(\mathbf{0})<$ or $=0.1 ;(1)>0.1$.

77. Cuneiform: position relative to scapholunar (Munson, 1992; Weisbecker and Archer, 2008): (0) Directly lateral to scapholunar; (1) More proximal than the scapholunar.

78. Cuneiform: ridge between ulnar and pisiform facets (Weisbecker and Archer, 2008): (0) Middle section sinks below the rim of the cuneiform; (1) High rising throughout, straight.

79. Pisiform: area of ulnar facet (Munson, 1992; Weisbecker and Archer, 2008): (0) < area of cuneiform facet; (1) $>$ or $=$ area of cuneiform facet.

80. Pisiform: width divided by thickness (Munson, 1992): $(0)<0.5$; (1) > or $=0.5$.

81. Scaphoid: distal surface (Weisbecker and Archer, 2008): (0) Single facet, smooth; (1) Separated into two distinct facets.

82. Scaphoid: distolateral process (Weisbecker and Sánchez-Villagra, 2006): (0) Absent; (1) Present.

83. Unciform: area of $M C \vee$ facet (Munson, 1992; Weisbecker and Archer, 2008): (0) < MC IV facet; (1) > or = area of MC IV facet.

84. Unciform: hamate process (modified from Munson, 1992, Weisbecker and Sánchez-
Villagra, 2006 and Weisbecker and Archer, 2008): (0) Large, hooked and curves medially; (1) Reduced, not as hooked and does not curve as far medially.

85.* MC I: max. width divided by length (modified from Munson, 1992 by Weisbecker and Archer, 2008): (0) < 0.4 ; (1) 0.4 to 0.5 ; (2) $>0.5$.

86. MC II: proximal end (Munson, 1992; Weisbecker and Archer, 2008): (0) Mediolaterally compressed; (1) Expanded and concave.

87. MC III: facet for MC IV (modified from Munson, 1992): (0) Proximal only to ligament pit (no dorsal component); (1) Dorsal to ligament pit (no proximal component); (2) Dorsal and proximal to ligament pit.

88. MC III: facet for MC IV (modified from Munson, 1992 by Weisbecker and Archer, 2008): (0) Facing laterally or only slightly distally slanted; (1) Strongly distally slanted or completely facing distally.

89. MC III: magnum facet (modified from Munson 1992): (0) Grooved or concave; (1) Convex or flat to slightly convex.

90. MC III: MC II facet (Munson, 1992; Weisbecker and Archer, 2008): (0) Separate, distinct, and lateral to the magnum facet; (1) Continuous with the magnum facet.

91.* MC V: max. width of distal end divided by length (modified from Munson, 1992 and Weisbecker and Archer, 2008): (0) < 0.4; (1) 0.4 to 0.5 ; (2) > 0.5 .

92.* Proximal phalanges II to $\mathrm{V}$ of manus, IV and $\mathrm{V}$ only in pes: mid-shaft width divided by length (modified from Munson, 1992 and Weisbecker and Archer, 2008): (0) < 0.3 ; (1) 0.3 to 0.4 ; (2) $>0.4$.

93. Proximal phalanges, manus or pes: distal ends (Munson, 1992; Weisbecker and Archer, 2008): (0) Not tapered; (1) Dorsoventrally tapered, so that the articulation for the medial phalanx faces ventrally.

94.* Medial phalanx III of manus or IV of pes: length divided by length of corresponding metapodial (modified from Munson, 1992 and Weisbecker and Archer, 2008): (0) < 0.30 ; (1) 0.30 to 0.40 ; (2) $>0.40$.

95. Pelvis: dorsoventral height at symphysis divided by width at mid-ischium (Munson, 1992): (0) <0.8; (1) > or $=0.8$. 
96. Pelvis: ilium (Munson, 1992): (0) Only slightly dorsoventrally flattened, or mediolaterally flattened; (1) Greatly dorsoventrally flattened.

97.* Pelvis: width of iliac crest divided by length of ilium (Munson, 1992): (0) < 0.30; (1) 0.30 to $0.50 ;(2)>0.50$.

98. Epipubics: width at mid-bone divided by length X 100 (Munson, 1992): (0) < 10; (1) $>$ or $=10$.

99. Femur: width of proximal end divided by length (Munson, 1992): (0) < 0.3; (1) > or = 0.3 .

100. Tibia: length (Munson, 1992): $(\mathbf{0})>$ or $=$ length of femur; (1) < length of femur.

101. Fibula: lateral notch on distal end (Munson, 1992): (0) Clearly present; (1) Extremely slight or absent.

102. Fibula: width of proximal end divided by bone length (modified from Munson, 1992): (0) < 0.10; (1) > or $=0.10$.

103. Fibula: femoral facet (Munson, 1992): (0) Not present; (1) Present.

104. Astragalus: lateral tibial facet (modified from Munson, 1992): (0) Mostly convex; (1) Mostly concave.

105. Astragalus: head (modified from Munson, 1992): (0) Wider than long; (1) Narrow, mediolaterally compressed, or length and width are equal.
106. Cuboid (Munson, 1992): (0) No contact; (1) Contacts astragalus.

107. Cuboid: area of MT $\vee$ facet (Munson, 1992): (0) < MT IV facet; (1) > or = area of MT IV facet.

108. Ectocuneiform: length divided by height (Munson, 1992): (0) > or =0.8; (1) < 0.8 .

109. Entocuneiform: MT I facet (Munson, 1992): (0) Saddle-shaped (concavo-convex); (1) Convex.

110. Entocuneiform: navicular facet (Munson, 1992): (0) Shorter than or equal to mesocuneiform facet; (1) Longer than mesocuneiform facet.

111. Metatarsal I: entocuneiform facet (Munson, 1992): (0) Mostly convex; (1) Strong concave component.

112. MT II and III: mid-shaft width divided by bone length (Munson, 1992): (0) $<0.15$; (1) $>$ or $=0.15$.

113. MT IV: proximal end (Munson, 1992): (0) Square; (1) Mediolaterally tapered.

114. MT V versus MT III (modified from Munson, 1992): (0) MT III longer that MT V; (1) MT V longer than MT III.

115.* MT V: max. width divided by length (modified from Munson, 1992): (0) < 0.50; (1) 0.50 to $0.70 ;(2)>0.70$. 


\section{APPENDIX 2.}

Data matrix used for phylogenetic analysis. ? indicates missing data; - indicates inapplicable character; polymorphic states indicated by both states in brackets, e.g., (01).

\begin{tabular}{|c|c|}
\hline Didelphis marsupialis & $\begin{array}{l}00001000000-0112020100000011000001000000000 ? 00020000 ? 001000010-1000000 \\
\text { 0???????? ????????? ????00000? ????????? ????? }\end{array}$ \\
\hline Perameles bougainville & 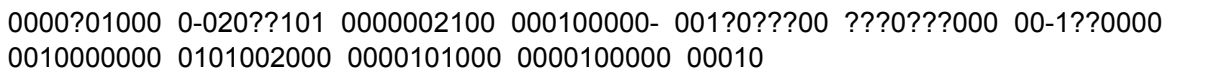 \\
\hline Galadi speciosus & $\begin{array}{l}00000020000-000 ?+001000 ? 00110000010000000000000 ? 000000100 ? 0010-1000 ? ? ? \\
\text { ????????? ????????? ????101?0? ????????? ????? }\end{array}$ \\
\hline Ngapakaldia tedfordi & 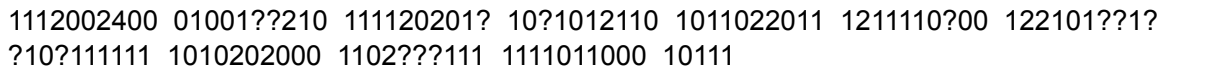 \\
\hline Ilaria ilumindens & $\begin{array}{l}110210210 ? 0-0112120011 \text { 11?110??? ???1??1??? 201??????? ??? } \\
\text { ?111?0???? ????111111 ?11??????? ????????? ??1?? }\end{array}$ \\
\hline $\begin{array}{l}\text { Propalorchestes } \\
\text { novaculocephalus }\end{array}$ & $\begin{array}{l}\text { ??12002300 } 010012121011112010 ? ? 11012122102021021 ? 11121111 ? 2101221111 ? ? ? ? \\
\text { ????????? ????????? ????????? ?????????? ????? }\end{array}$ \\
\hline Nimiokoala greystanesi & $\begin{array}{l}10021021000-02101001001001001000 \text { 001?0?010 } 1030 ? 1+? 00 \text { ??000????0 } 13000 \\
\text { ????????? ????????? ????????? ????????? ????? }\end{array}$ \\
\hline Priscileo roskellyae & $\begin{array}{l}11000002000-011 \text { (?) } 10110101010 ? ? 0001 ? 00000 \text { ?030011200 ?210100??0 ?10001???? } \\
\text { ????????? ????????? ????????? ????????? ????? }\end{array}$ \\
\hline Lasiorhinus latifrons & $\begin{array}{l}2-12 ? 1 ? 21120001012(01) 00011 ? 0100110111211(01) 10120122000121011112113111111111 \\
211110111110 ? 121 ? 11122110121111111011111 ?+1102\end{array}$ \\
\hline $\begin{array}{l}\text { Nimbavombatus } \\
\text { boodjamullensis }\end{array}$ & $\begin{array}{l}1 \text { 1?02012201 } 1011 \text { ?????0 00???????? ??01?10??? 0020?????? ?????????? ?????????? } \\
\text { ?????????? ?????????? ?????????? ?????????? ????? }\end{array}$ \\
\hline Phascolonus gigas & $\begin{array}{l}\text { 2-12?0??11 2?0??????0 ?011?????? ?1101?12?1 01?01????? ?2?????122 } 03011111111 \\
\text { 2111111111 1?1121?1?1 221?112011 11110????? ????? }\end{array}$ \\
\hline Rhizophascolonus crowcrofti & $\begin{array}{l}\text { ???????201 (12)?1??????0 ?????????? ?????????? ?????????? ?????????0 1???? } \\
\text { ?????????? ?????????? ?????????? ?????????? ????? }\end{array}$ \\
\hline Vombatus ursinus & $\begin{array}{lllllll}2-12 ? 1 ? 211 & 20011012 ? 0 & 1010 ? 01101 & (01) 000021111 & 0120122 ? 00 & 1110111212 & 1311111111 \\
1111111111 & 1001211111 & 2211012111 & 1111011111 & 11102 & & \end{array}$ \\
\hline Warendja wakefieldi & $\begin{array}{l}\text { 2-12?1??11 2?0??????0 ?010?????? ?001?10??0 } 00101220 ? ? \text { ?1?01????0 } 0210110 ?+1 \\
1 \text { 1???????? ????????? ????????? ????????? ????? }\end{array}$ \\
\hline Muramura williamsi & $\begin{array}{l}11020 ? 020000 ? 100 ? 20110111010101000 ? 0 ? 1 ? 0 \text { 20100????? 01??1?1110 } 11210 ? 0000 \\
\text { 000000???? ????????? ???????11 0111??0??? ????? }\end{array}$ \\
\hline Marada ar & $\begin{array}{l}\text { ???????200 00???????? ??11101010 1????????? ?????????? ?????????00 } 0121010 \\
\text { ?????????? ?????????? ?????????? ?????????? ????? }\end{array}$ \\
\hline
\end{tabular}




\section{APPENDIX 3.}

Comparative dental measurements.

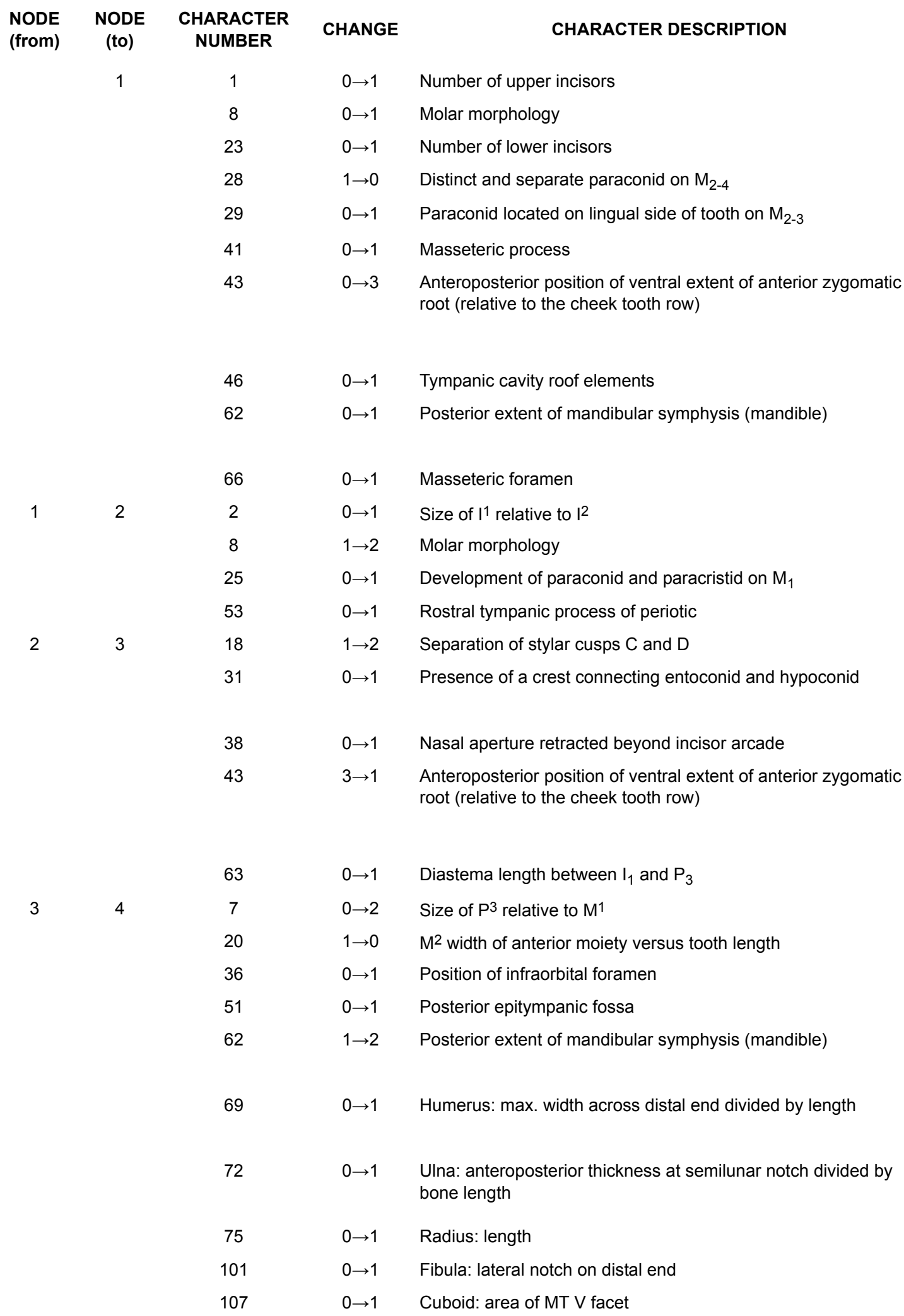




\begin{tabular}{|c|c|c|c|c|}
\hline $\begin{array}{l}\text { NODE } \\
\text { (from) }\end{array}$ & $\begin{array}{l}\text { NODE } \\
\text { (to) }\end{array}$ & $\begin{array}{l}\text { CHARACTER } \\
\text { NUMBER }\end{array}$ & CHANGE & CHARACTER DESCRIPTION \\
\hline \multirow[t]{12}{*}{4} & 5 & 3 & $0 \rightarrow 1$ & Upper canine \\
\hline & & 8 & $2 \rightarrow 3$ & Molar morphology \\
\hline & & 12 & $0 \rightarrow 1$ & Anteriorly concave lower / anteriorly convex upper molar lophs \\
\hline & & 14 & $1 \rightarrow 0$ & Parastyle development on $\mathrm{M}^{1}$ \\
\hline & & 19 & $0 \rightarrow 1$ & Postprotocrista \\
\hline & & 25 & $1 \rightarrow 2$ & Development of paraconid and paracristid on $\mathrm{M}_{1}$ \\
\hline & & 37 & $1 \rightarrow 2$ & Posterior palatal vacuities (maxillopalatine vacuity) \\
\hline & & 44 & $0 \rightarrow 1$ & Infraorbital shelf \\
\hline & & 49 & $0 \rightarrow 1$ & Epitympanic fenestra developed in postglenoid cavity \\
\hline & & 50 & $0 \rightarrow 1$ & Non-auditory sinuses \\
\hline & & 52 & $1 \rightarrow 2$ & Postglenoid cavity / epitympanic fossa \\
\hline & & 54 & $0 \rightarrow 1$ & Posterior parietal width \\
\hline \multirow[t]{6}{*}{4} & 6 & 86 & $0 \rightarrow 1$ & MC II: proximal end \\
\hline & & 87 & $2 \rightarrow 1$ & MC III: facet for MC IV \\
\hline & & 88 & $0 \rightarrow 1$ & MC III: facet for MC IV \\
\hline & & 89 & $0 \rightarrow 1$ & MC III: magnum facet \\
\hline & & 90 & $0 \rightarrow 1$ & MC III: MC II facet \\
\hline & & 93 & $0 \rightarrow 1$ & Proximal phalanges, manus or pes: distal ends \\
\hline \multirow[t]{3}{*}{6} & 7 & 6 & $0 \rightarrow 1$ & $\begin{array}{l}\text { Enamel extending down the buccal surface of } \mathrm{P}_{3} \text { and onto the } \\
\text { root }\end{array}$ \\
\hline & & 11 & $0 \rightarrow 1$ & $\begin{array}{l}\text { Presence of enamel tracts that extends down the lingual surface } \\
\text { of upper molars and buccal surface of lower molars }\end{array}$ \\
\hline & & 41 & $1 \rightarrow 0$ & Masseteric process \\
\hline \multirow[t]{3}{*}{7} & 8 & 3 & $0 \rightarrow 1$ & Upper canine \\
\hline & & 9 & $0 \rightarrow 1$ & Hypselodont cheek teeth \\
\hline & & 11 & $1 \rightarrow 2$ & $\begin{array}{l}\text { Presence of enamel tracts that extends down the lingual surface } \\
\text { of upper molars and buccal surface of lower molars }\end{array}$ \\
\hline \multirow[t]{5}{*}{8} & 9 & 36 & $1 \rightarrow 2$ & Position of infraorbital foramen \\
\hline & & 40 & $0 \rightarrow 1$ & $\begin{array}{l}\text { Separate left and right parietal ridges along entire length of } \\
\text { parietal bone }\end{array}$ \\
\hline & & 42 & $0 \rightarrow 1$ & $\begin{array}{l}\text { Dorsoventral position of ventral extent of anterior zygomatic root } \\
\text { (relative to the cheek tooth row) }\end{array}$ \\
\hline & & 60 & $0 \rightarrow 1$ & Depth of masseteric fossa (mandible) \\
\hline & & 62 & $2 \rightarrow 3$ & Posterior extent of mandibular symphysis (mandible) \\
\hline
\end{tabular}


BREWER ET AL.: NEW WOMBAT FROM RIVERSLEIGH

\begin{tabular}{|c|c|c|c|c|}
\hline $\begin{array}{l}\text { NODE } \\
\text { (from) }\end{array}$ & $\begin{array}{l}\text { NODE } \\
\text { (to) }\end{array}$ & $\begin{array}{l}\text { CHARACTER } \\
\text { NUMBER }\end{array}$ & CHANGE & CHARACTER DESCRIPTION \\
\hline \multirow[t]{5}{*}{9} & 10 & 33 & $0 \rightarrow 1$ & Lateral edge of palate emarginated from $\mathrm{I}^{1}$ to $\mathrm{P}^{3}$ in ventral view \\
\hline & & 35 & $0 \rightarrow 1$ & Median premaxillary process \\
\hline & & 52 & $1 \rightarrow 2$ & Postglenoid cavity / epitympanic fossa \\
\hline & & 59 & $1 \rightarrow 2$ & Forward extent of ectalveolar groove of mandible \\
\hline & & 71 & $1 \rightarrow 2$ & Humerus: deltoid tuberosity \\
\hline 8 & 11 & 13 & $0 \rightarrow 1$ & $\begin{array}{l}\mathrm{M}^{1} \text { with decrease in enamel height on lingual surface at } \\
\text { constriction or just posterior to this }\end{array}$ \\
\hline
\end{tabular}




\section{APPENDIX 4.}

Cusp morphology of P3 to M2 of modern wombats compiled from CT scans of Lasiorhinus latifrons (SAM M4157 and SAM M1924) and Vombatus ursinus (MNV C19028 and MNV C3133). 1, Upper dentition of L. latifrons. 2, Upper dentition of $V$. ursinus. 3, Lower dentition of $L$. latifrons. 4, Lower dentition of $V$. ursinus. Abbreviations as follows: end refers to entoconid, hyd refers to hypoconid, ME refers to metacone, med refers to metaconid, MEL refers to metaconule, PA refers to paracone, PR refers to protocone, prd refers to protoconid.

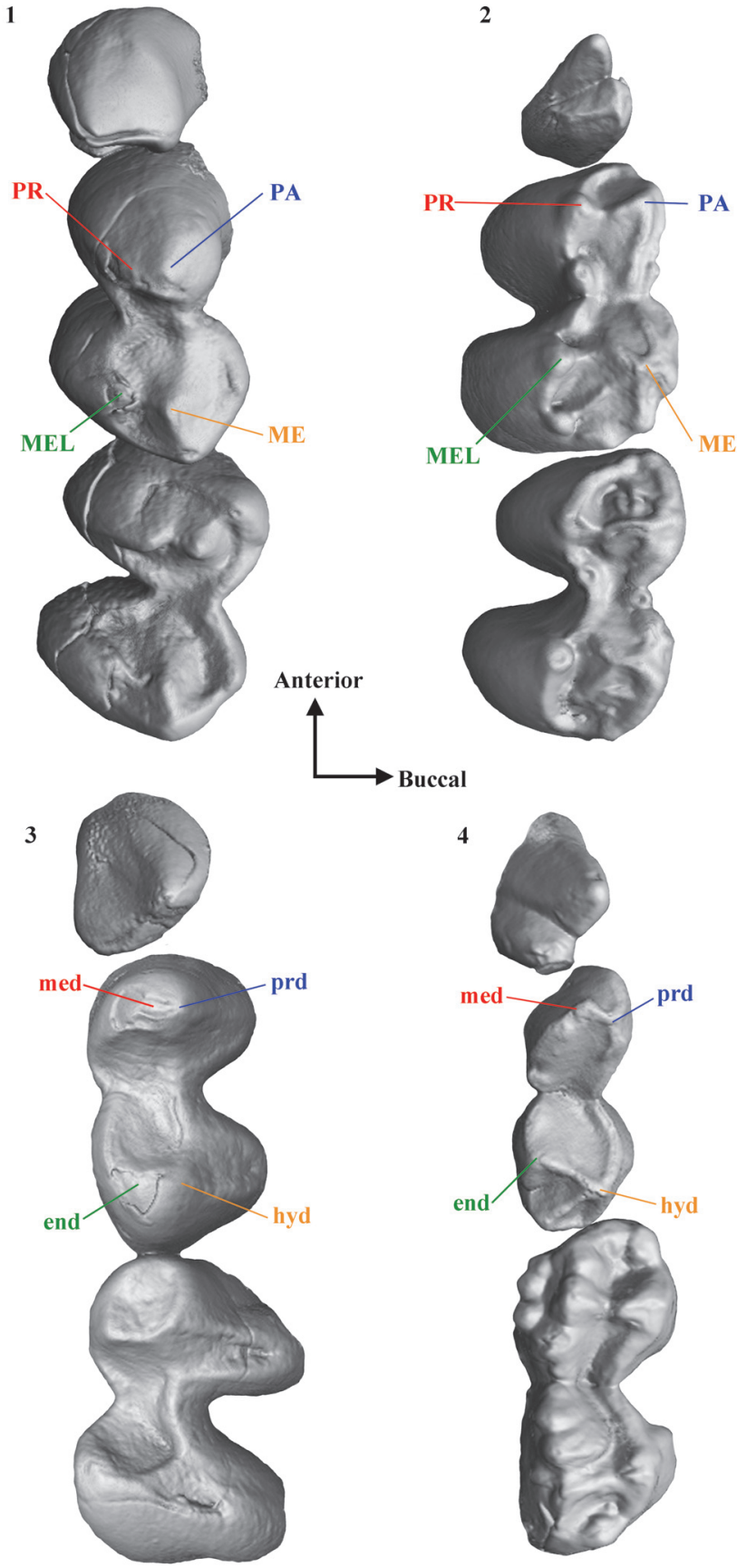




\section{APPENDIX 5.}

List of unambiguous apomorphies. Node numbers correspond to Figure 7.2

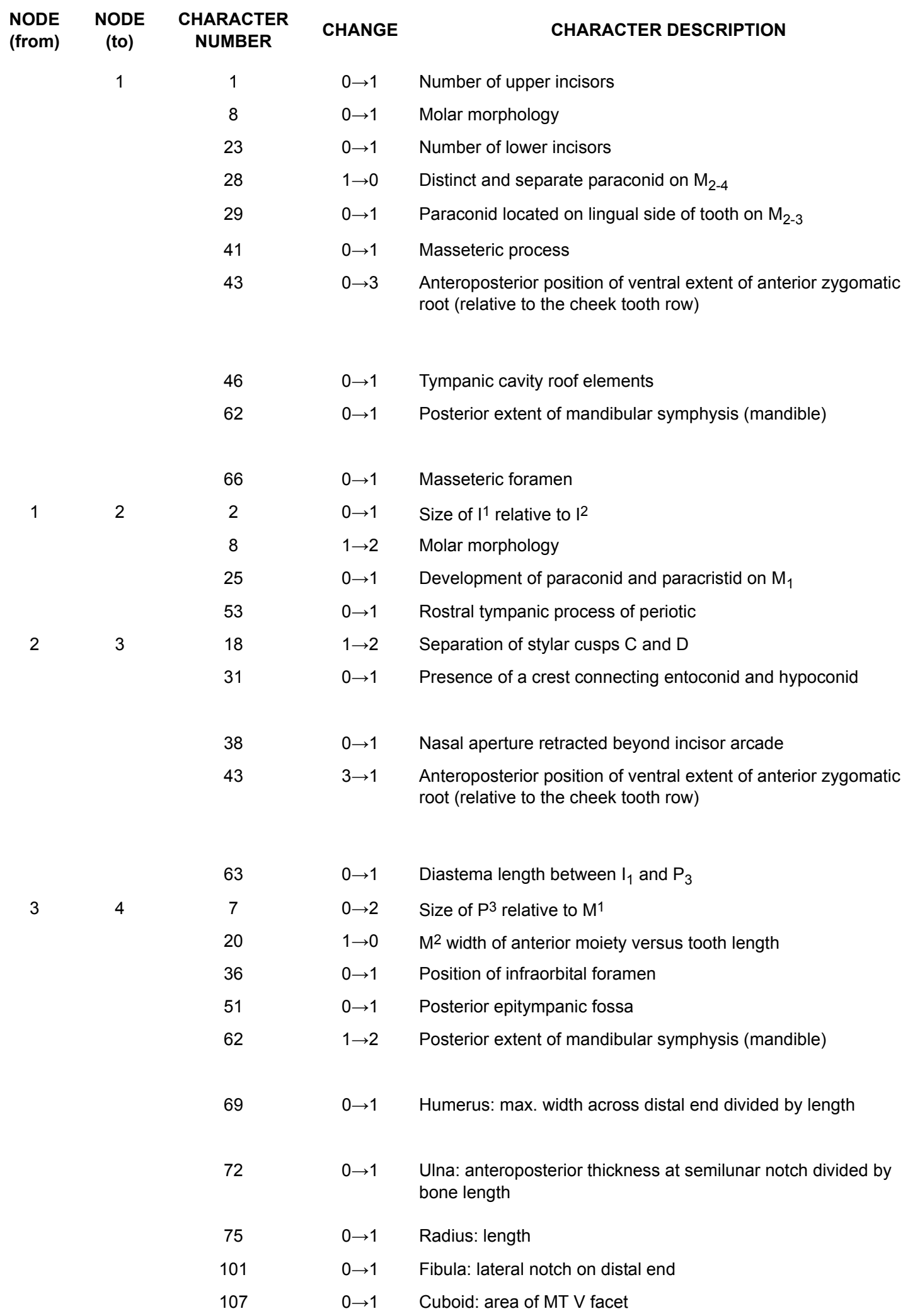




\begin{tabular}{|c|c|c|c|c|}
\hline $\begin{array}{l}\text { NODE } \\
\text { (from) }\end{array}$ & $\begin{array}{l}\text { NODE } \\
\text { (to) }\end{array}$ & $\begin{array}{l}\text { CHARACTER } \\
\text { NUMBER }\end{array}$ & CHANGE & CHARACTER DESCRIPTION \\
\hline \multirow[t]{12}{*}{4} & 5 & 3 & $0 \rightarrow 1$ & Upper canine \\
\hline & & 8 & $2 \rightarrow 3$ & Molar morphology \\
\hline & & 12 & $0 \rightarrow 1$ & Anteriorly concave lower / anteriorly convex upper molar lophs \\
\hline & & 14 & $1 \rightarrow 0$ & Parastyle development on $\mathrm{M}^{1}$ \\
\hline & & 19 & $0 \rightarrow 1$ & Postprotocrista \\
\hline & & 25 & $1 \rightarrow 2$ & Development of paraconid and paracristid on $\mathrm{M}_{1}$ \\
\hline & & 37 & $1 \rightarrow 2$ & Posterior palatal vacuities (maxillopalatine vacuity) \\
\hline & & 44 & $0 \rightarrow 1$ & Infraorbital shelf \\
\hline & & 49 & $0 \rightarrow 1$ & Epitympanic fenestra developed in postglenoid cavity \\
\hline & & 50 & $0 \rightarrow 1$ & Non-auditory sinuses \\
\hline & & 52 & $1 \rightarrow 2$ & Postglenoid cavity / epitympanic fossa \\
\hline & & 54 & $0 \rightarrow 1$ & Posterior parietal width \\
\hline \multirow[t]{6}{*}{4} & 6 & 86 & $0 \rightarrow 1$ & MC II: proximal end \\
\hline & & 87 & $2 \rightarrow 1$ & MC III: facet for MC IV \\
\hline & & 88 & $0 \rightarrow 1$ & MC III: facet for MC IV \\
\hline & & 89 & $0 \rightarrow 1$ & MC III: magnum facet \\
\hline & & 90 & $0 \rightarrow 1$ & MC III: MC II facet \\
\hline & & 93 & $0 \rightarrow 1$ & Proximal phalanges, manus or pes: distal ends \\
\hline \multirow[t]{3}{*}{6} & 7 & 6 & $0 \rightarrow 1$ & $\begin{array}{l}\text { Enamel extending down the buccal surface of } \mathrm{P}_{3} \text { and onto the } \\
\text { root }\end{array}$ \\
\hline & & 11 & $0 \rightarrow 1$ & $\begin{array}{l}\text { Presence of enamel tracts that extends down the lingual surface } \\
\text { of upper molars and buccal surface of lower molars }\end{array}$ \\
\hline & & 41 & $1 \rightarrow 0$ & Masseteric process \\
\hline \multirow[t]{3}{*}{7} & 8 & 3 & $0 \rightarrow 1$ & Upper canine \\
\hline & & 9 & $0 \rightarrow 1$ & Hypselodont cheek teeth \\
\hline & & 11 & $1 \rightarrow 2$ & $\begin{array}{l}\text { Presence of enamel tracts that extends down the lingual surface } \\
\text { of upper molars and buccal surface of lower molars }\end{array}$ \\
\hline \multirow[t]{5}{*}{8} & 9 & 36 & $1 \rightarrow 2$ & Position of infraorbital foramen \\
\hline & & 40 & $0 \rightarrow 1$ & $\begin{array}{l}\text { Separate left and right parietal ridges along entire length of } \\
\text { parietal bone }\end{array}$ \\
\hline & & 42 & $0 \rightarrow 1$ & $\begin{array}{l}\text { Dorsoventral position of ventral extent of anterior zygomatic root } \\
\text { (relative to the cheek tooth row) }\end{array}$ \\
\hline & & 60 & $0 \rightarrow 1$ & Depth of masseteric fossa (mandible) \\
\hline & & 62 & $2 \rightarrow 3$ & Posterior extent of mandibular symphysis (mandible) \\
\hline
\end{tabular}


BREWER ET AL.: NEW WOMBAT FROM RIVERSLEIGH

\begin{tabular}{|c|c|c|c|c|}
\hline $\begin{array}{l}\text { NODE } \\
\text { (from) }\end{array}$ & $\begin{array}{l}\text { NODE } \\
\text { (to) }\end{array}$ & $\begin{array}{l}\text { CHARACTER } \\
\text { NUMBER }\end{array}$ & CHANGE & CHARACTER DESCRIPTION \\
\hline \multirow[t]{5}{*}{9} & 10 & 33 & $0 \rightarrow 1$ & Lateral edge of palate emarginated from $\mathrm{I}^{1}$ to $\mathrm{P}^{3}$ in ventral view \\
\hline & & 35 & $0 \rightarrow 1$ & Median premaxillary process \\
\hline & & 52 & $1 \rightarrow 2$ & Postglenoid cavity / epitympanic fossa \\
\hline & & 59 & $1 \rightarrow 2$ & Forward extent of ectalveolar groove of mandible \\
\hline & & 71 & $1 \rightarrow 2$ & Humerus: deltoid tuberosity \\
\hline 8 & 11 & 13 & $0 \rightarrow 1$ & $\begin{array}{l}\mathrm{M}^{1} \text { with decrease in enamel height on lingual surface at } \\
\text { constriction or just posterior to this }\end{array}$ \\
\hline
\end{tabular}

